\title{
Safe Motherhood Applied Research and Training (SMART) Report 2: The interventions
}

\author{
Abdul Wajid \\ Population Council \\ Zakir Hussain Shah \\ Ashfa Hashmi \\ Population Council \\ Zeba Tasneem \\ Population Council \\ Lubna Shireen \\ Population Council
}

Follow this and additional works at: https://knowledgecommons.popcouncil.org/departments_sbsr-rh

Part of the Demography, Population, and Ecology Commons, Family, Life Course, and Society Commons, Gender and Sexuality Commons, International Public Health Commons, Maternal and Child Health Commons, and the Medicine and Health Commons How does access to this work benefit you? Let us know!

\section{Recommended Citation}

Wajid, Abdul, Zakir Hussain Shah, Ashfa Hashmi, Zeba Tasneem, and Lubna Shireen. 2006. "Safe Motherhood Applied Research and Training (SMART) Report 2: The interventions." Islamabad: Population Council. 
Safe Motherhood Applied Research \& Training SMART
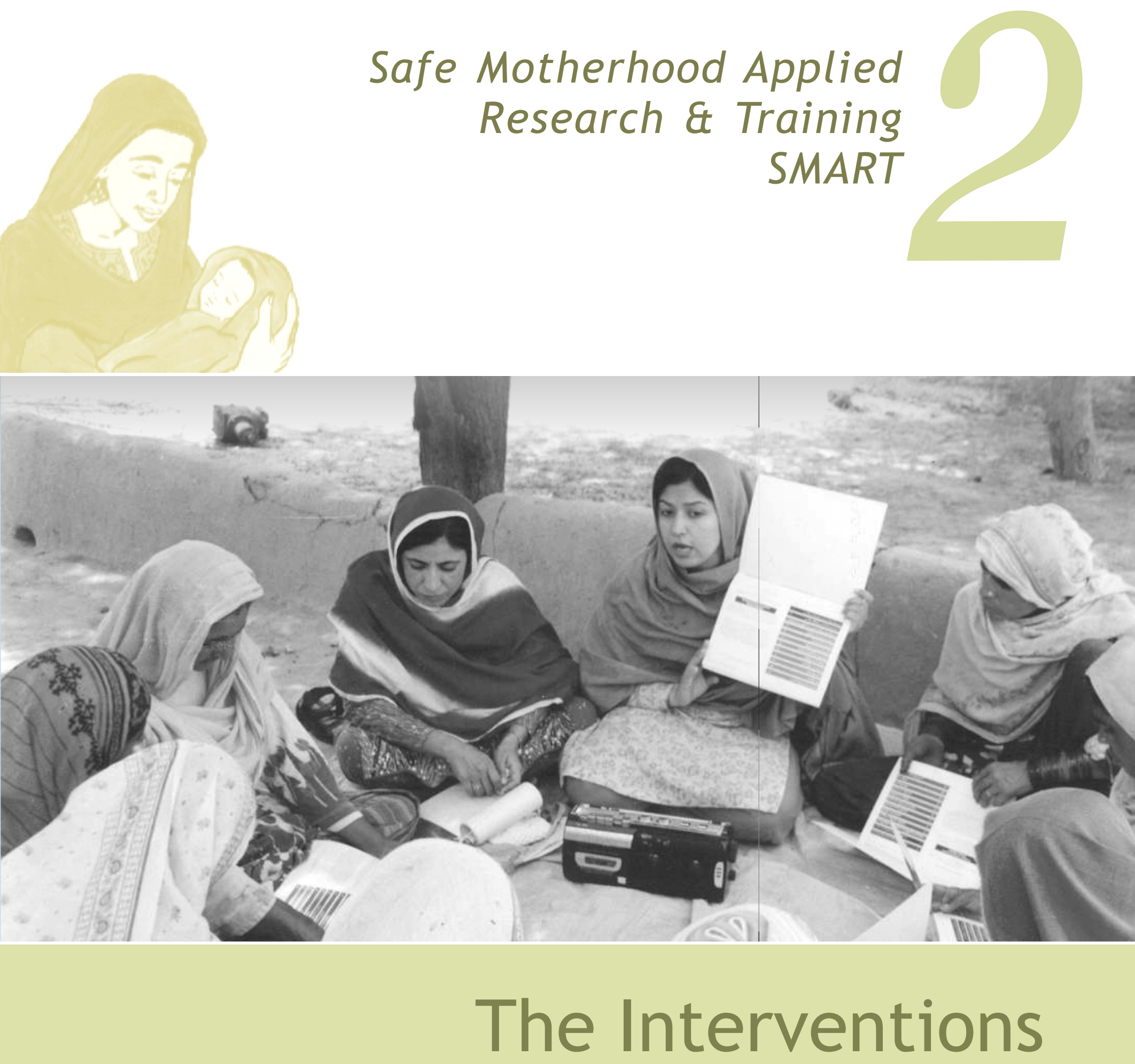

(1) Population Council

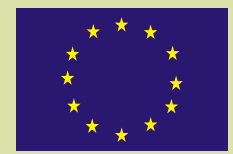





\section{Safe Motherhood Applied Research \& Training Project \\ SMART}

\section{SMART Report 2. \\ The Interventions}

Abdul Wajid

Zakir H. Shah Ashfa Hashmi

Zeba Tasneem

Lubna Shireen

Compiled and edited by Pamela J. Ledbetter 


\section{(2) Population Council}

The Population Council, an international, non-profit, nongovernmental organization established in 1952, seeks to improve the well-being and reproductive health of current and future generations around the world and to help achieve a humane, equitable, and sustainable balance between people and resources.

The Council analyzes population issues and trends; conducts research in the reproductive sciences; develops new contraceptives; works with public and private agencies to improve the quality and outreach of family planning and reproductive health services; helps governments design and implement effective population policies; communicates the results of research in the population field to diverse audiences; and helps strengthen professional resources in developing countries through collaborative research and programs, technical exchanges, awards, and fellowships.

\section{For inquiries, please contact:}

\section{Population Council}

House \#7, Street 62, F-6/3, Islamabad, Pakistan

Tel: 92512277439

Fax: 92512821401

Email: info@pcpak.org

Web: http://www.popcouncil.org

Layout \& Design: Mehmood Asghar \& Ali Ammad

Printed by: Crystal Printers

Published: December 2006

The Population Council reserves all rights of ownership of this document. No part of this publication may be reproduced, stored or transmitted in any form by any means electronic, photocopying, recording or otherwise - without the permission of the Population Council. 


\section{Safe Motherhood Applied Research and Training Project (SMART)}

The Safe Motherhood Applied Research and Training (SMART) project, and operations research project designed to develop and test interventions to reduce maternal, perinatal and neonatal mortality and morbidity in predominantly rural districts of Pakistan, was a three-year project funded by the European Union. Project implementation ran from October 2003 to October 2006. The study area was in the district of Dera Ghazi Khan; the control area was in the district of Layyah.

The project focused on three areas as a means of accomplishing its goals: empowering women to seek appropriate and timely general, maternal and newborn care; supporting methods that encourage men to play a positive and active role in decisionmaking and seeking care for their families in matters relating to maternal and newborn care; and improving and strengthening health services.

The project had two intervention sites and one control site in order to look at the impact of two different interventions (within communities and within health facilities). It was expected that project results would be useful to others working toward reducing maternal, perinatal and neonatal mortality and morbidity, nationally and internationally.

The interventions and findings from this study are published in six reports, which are available from the Population Council.

SMART Report 1. Project Overview

SMART Report 2. The Interventions

SMART Report 3. Change in Knowledge and Behavior of Women and Families

SMART Report 4. Knowledge and Behavior of Service Providers

SMART Report 5. Verbal Autopsies of Infant and Maternal Death

SMART Report 6. Formative Research on Maternal and Neonatal Health 


\section{Acknowledgments}

The Safe Motherhood and Applied Research and Training Project was an operations research project conducted in DG Khan through the financial support of the European Union; we gratefully acknowledge their support.

This report on the SMART interventions presents the activities that were implemented to provide safe motherhood outcomes for the pregnant women and newborns, and their families, in the district of DG Khan. This report is the result of the efforts of a large team working diligently, with wholehearted devotion and professional excellence, through all phases of project implementation and report writing.

We are especially thankful to Dr. Zeba Sathar for her overall leadership throughout the intervention and project period. It was due to her visionary input and contribution that we were able to formulate and finalize the intervention packages; later on her support and guidance made it possible to implement the interventions in the best possible way.

We are highly indebted to Dr. Farid Midhet who conceptualized the SMART intervention package in its original form and provided the guidelines to shape the interventions during the early stages.

Our special regards go to Mr. Peter C. Miller who led the SMART project from its initial phase of intervention until the completion of this report. Mr. Miller is, and has been, a continuous source of guidance and support for each member of the SMART team.

The project could not have been carried out in any more capable hands than those of Dr. Gul Rashida. Her leadership, her sense of responsibility and her devotion both to the project and to her staff are without parallel.

We are thankful to the Executive District Officer Health and the Director of the District Development Center (DG Khan), and their staff, for providing us with training facilities at the DHDC. We especially thank Dr. Ghazala Mehmood, Head of Gynecology and Obstetrics Department, Pakistan Institute of Medical Sciences, as well as the Executive Director of PIMS, Islamabad, for arranging the training of maternal and child health teams from DG Khan in comprehensive emergency obstetric care.

We are especially thankful to the staff of the National Rural Support Program of DG Khan, 
who carried out the fieldwork for community mobilization in twenty-two clusters, with the help of their community workers.

We are thankful to Dr. Ali Mir and Ms Seemin Ashfaq, who provided valuable input during the interventions, and in the development of information and education for empowerment and change (IEEC) materials, and imparted the leadership training to the health managers of DG Khan. We are thankful to our consultants who developed and organized the training curricula for the service providers: Dr. Farasat Bukhari for restructuring the traditional birth attendant and LHW curricula and for carrying out training of trainers; and Dr. Farhana Zareef for work on the training manuals for technical training of doctors and paramedics in emergency obstetric care, and for carrying out the training of trainers.

The authors received valuable comments on the content of the IEEC material during its development from Dr. Farid Midhet, Dr. Sadiqua N. Jafarey, Mrs. Imtiaz T. Kamal and Mr. Shafique Arif.

We are also thankful to Mr. Fakhar Baloch, Mr. Ahmed Kabir Syed and Mr. Malik Aziz ur Rehman, Station Directors, Radio Pakistan, Islamabad, Multan and Quetta, respectively, for giving long hours to recording the IEEC audiocassette. Mr. Naveed Ansari, IT Recorder, was instrumental in recording the audiocassette at Radio Pakistan, Multan.

Mr. Minhaj ul Haq, Ms Munawar Sultana and Mr. Enayat ur Rehman provided helpful input and comments in the pictorial parts of the IEEC material, making it sensitive to the local culture.

Ms Mashooda Mirza played a bridging role between the research teams in the field and Population Council's Islamabad office, with comments and guidance.

We would like to acknowledge the technical guidance of the Balochistan Safe Motherhood Initiative team, Ms Fazela and Mr. Abraham Jamli from Balochistan, in community mobilization activities.

We are grateful to continuous logistic and administrative support by Mr. Abrar Ahmed, Mr. Bader ul Islam, Mr. Abdur Rashid Bhatti, Mr. Rahim Dad, Mr. Bakht Munir, Mr. Samar, Mr. Akram Kamran Ghazanfar Abbasi and Mr. Khalid Qureshi. Mr. Imran Ahmed (Director, Admintration and Finance) played a leading role in ensuring timely provision of support services during all stages of intervention and report writing. 
The report was initially edited by Ms Reem Khan, under the guidance of Mr. Peter Miller. Mr. Mehmood Asghar and Mr. Khurram Shehzad brought the IEEC booklet to a presentable shape, and Mr. Ali Ammad formatted and finalized the layout of this report. We must record our appreciation and gratitude to Pamela Ledbetter for her effort in consolidating and preparing the report's final version.

We are extremely grateful to all the trainers, supervisors, assistants, male logistic persons and other support staff, who helped in conducting the community-based and health service interventions. Their names are listed in appendix 9.

We warmly thank our trainees who traveled long distances and participated in the many hours of classroom training. We thank all of these men and women, health care providers and community members alike, who participated in training sessions, attended community meetings or participated in orientation sessions in order to achieve a safe experience for the mothers and newborns in their communities.

And, finally, our appreciation goes to the pregnant women and newborns of DG Khan, who were a continuing inspiration for the work of this project. We express our delight at having met the infants and children of DG Khan, for whom all project participants developed a lasting affection. 


\section{Table of Contents}

Section I. Smart Project Introduction........................................... 1

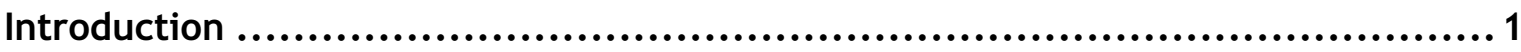

Pakistan Context ....................................................................... 1

DG Khan Context ...................................................................... 2

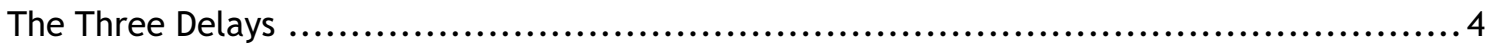

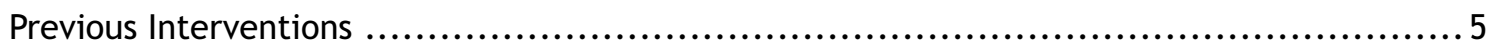

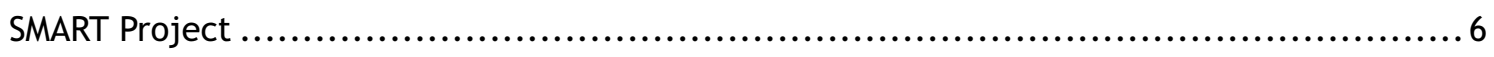

Presentation of Interventions in this Report ......................................... 10

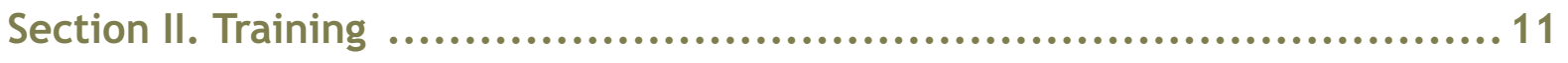

Community-Based Training

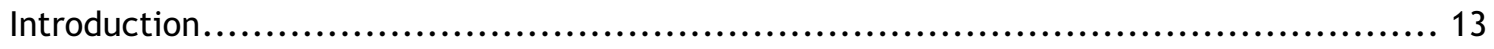

Lady Health Workers ............................................................. 15

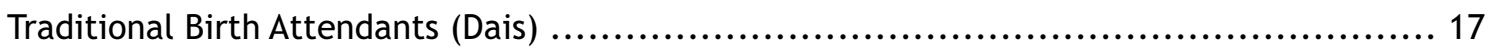

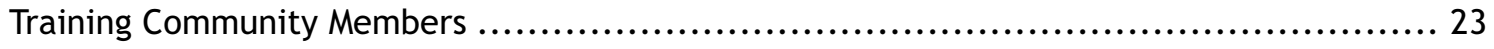

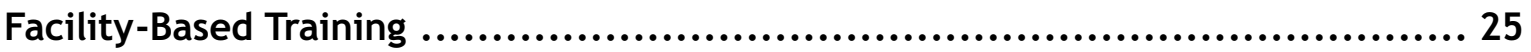

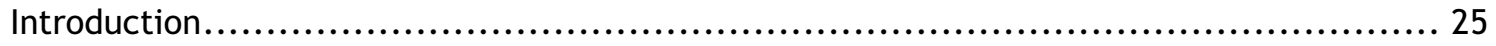

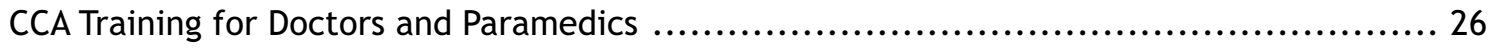

Comprehensive EmOC Training for Doctors and Paramedics ................................. 27

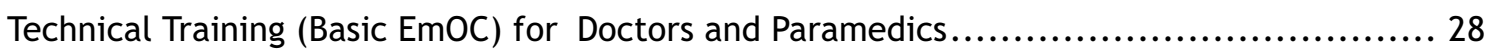

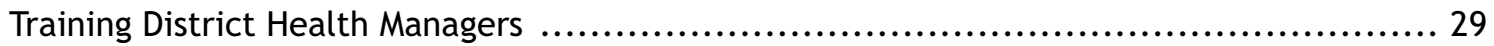

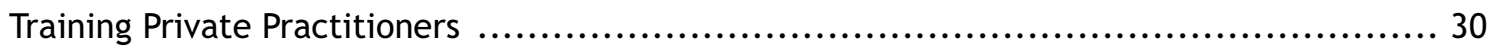

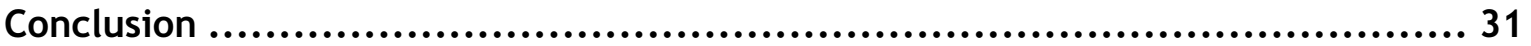

Section III. Community Mobilization and Education........................... 33

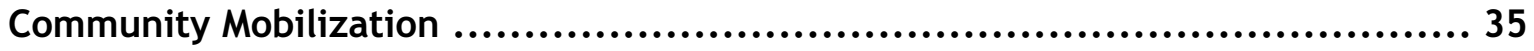

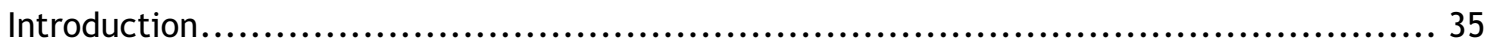

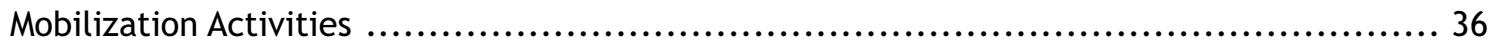

Information and Education for Empowerment and Change (IEEC) ................ 44

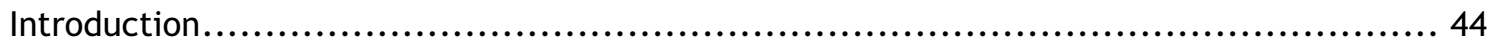

Conclusion ................................................................ 59

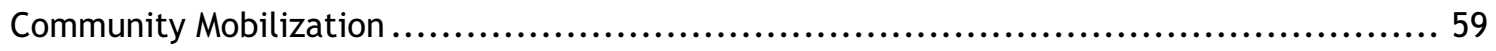

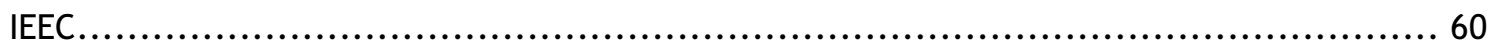




\section{Appendix}

Appendix 1. Description of client-centered approach training $\quad$..................... 65

Appendix 2. Training of trainers in the client-centered approach................. 67

Appendix 3. Description of dai training: client-centered approach and technical .... 69

Appendix 4. Manuals used in technical (basic EmOC) training of doctors and

paramedics........................................................ 71

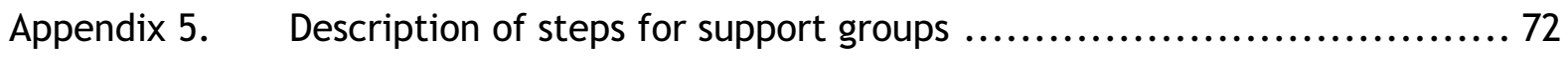

Appendix 6. Composition of focus groups for preparatory fieldwork............... 73

Appendix 7. Detailed description of IEEC booklet............................. 75

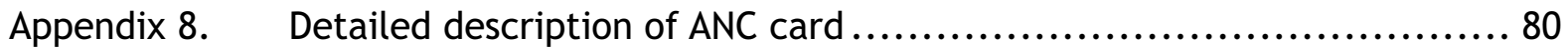

Appendix 9. Names of individuals involved in SMART interventions ................ 82 


\section{Abbreviations}

\begin{tabular}{|c|c|}
\hline ANC & Antenatal Care \\
\hline ADB & Asian Development Bank \\
\hline $\mathrm{BHU}$ & Basic Health Unit \\
\hline BSMI & Balochistan Safe Motherhood Initiative \\
\hline CBI & Community-Based Intervention \\
\hline $\mathrm{CBO}$ & Community-Based Organization \\
\hline CCA & Client-Centered Approach \\
\hline CMC & Community Mobilization Component \\
\hline DCR & District Census Report \\
\hline DG KHAN & Dera Ghazi Khan \\
\hline DHDC & District Health Development Center \\
\hline DHQ & District Headquarter Hospital \\
\hline DHDC & District Health Development Center \\
\hline EDO & Executive District Officer \\
\hline EmOC & Emergency Obstetric Care \\
\hline EmONC & Emergency Obstetric and Neonatal Care \\
\hline EmONF & Emergency Obstetric Neonatal Fund \\
\hline ENMR & Early Neonatal Mortality Rate \\
\hline EOC & Essential Obstetrical Care \\
\hline EU & European Union \\
\hline FGD & Focus Group Discussion \\
\hline FMT & Female Medical Technician \\
\hline $\mathrm{FP}$ & Family Planning \\
\hline F. Sterilization & Female Sterilization \\
\hline FWW & Family Welfare Workers \\
\hline HHS & Household Survey \\
\hline HSA & Health Services Assessment \\
\hline HSI & Health Services Intervention \\
\hline IDI & In-depth Interview \\
\hline IEEC & Information and Education for Empowerment and Change \\
\hline IEC & Information Education Communication \\
\hline IUCD & Intrauterine Contraceptive Device \\
\hline KAB & Knowledge, Attitude and Behavior \\
\hline LHW & Lady Health Worker \\
\hline LHS & Lady Health Supervisor \\
\hline
\end{tabular}




\begin{tabular}{|c|c|}
\hline LHV & Lady Health Visitor \\
\hline MCH Center & Maternal and Child Health Center \\
\hline MDG & Millennium Development Goals \\
\hline $\mathrm{MNH}$ & Maternal and Neonatal Health \\
\hline M. Sterilization & Male Sterilization \\
\hline MMR & Maternal Mortality Ratio \\
\hline $\mathrm{MO}$ & Medical Officer \\
\hline MT & Medical Technician \\
\hline MWRA & Married Women of Reproductive Age \\
\hline NRSP & National Rural Support Program \\
\hline NMR & Neonatal Mortality Rate \\
\hline OTT & Operation Theatre Technician \\
\hline PAIMAN & Pakistan Initiative for Mothers and Newborns \\
\hline PC & Population Council \\
\hline PHC & Primary Health Care \\
\hline PHF & Primary Health Facility (BHU/ RHC) \\
\hline PIMS & Pakistan Institute of Medical Sciences \\
\hline PNMR & Perinatal Mortality Rate \\
\hline PSLMS & Pakistan Social and Living Standard Measurement Survey \\
\hline PWD & Population Welfare Department \\
\hline $\mathrm{RHC}$ & Rural Health Center \\
\hline RHSC A & Reproductive Health Services Center - A \\
\hline SES & Socioeconomic Status \\
\hline SMART & Safe Motherhood Applied Research and Training \\
\hline SAHR & Salutation Assess Help Reassure \\
\hline SMAM & Singulate Mean Age at Marriage \\
\hline TBA & Traditional Birth Attendant \\
\hline TCL & Training at Community Level \\
\hline TFR & Total Fertility Rate \\
\hline THQ & Tehsil Headquarter Hospital \\
\hline TOT & Training of Trainers \\
\hline UNFPA & United Nations Fund for Population Activities \\
\hline VBFPW & Village Based Family Planning Worker \\
\hline $\mathrm{VC}$ & Village Committee \\
\hline $\mathrm{VHC}$ & Village Health Committee \\
\hline WMO & Woman Medical Officer \\
\hline
\end{tabular}




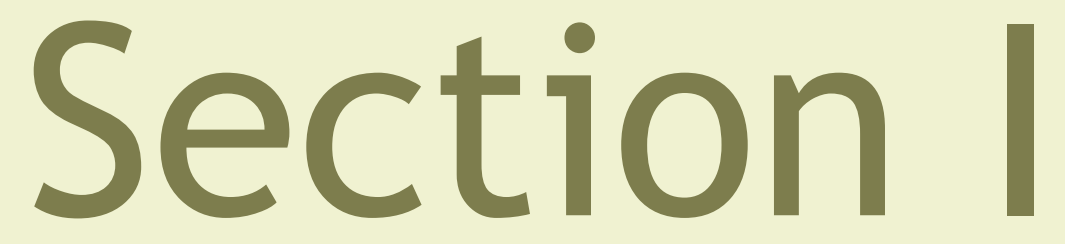

Smart Project Introduction 



\section{Introduction $^{1}$}

\section{Pakistan Context}

Pakistan is among the countries with high fertility and high maternal and infant mortality, despite advances in medical technology. An estimated 30,000 women die each year due to obstetric complications.

A disproportionate majority of these deaths occur in rural areas and urban slums. The maternal mortality ratio (MMR) varies between 100 and 700 per 100,000 live births, depending upon socioeconomic status and residence. Overall, the rate is estimated to be about 30,000 maternal deaths each year, or one maternal death every 20 minutes. This does not include those who suffer from temporary or permanent disabilities. Maternal deaths are largely due to antepartum and postpartum hemorrhage, eclampsia, puerperal sepsis, and obstructed labor. Neonatal mortality is about 48.9 per 1,000 live births and perinatal mortality, from hospital-based studies, is 92 per 1,000 births. Women having their first birth, women ages under 18 or over 34 years, and those having a previous history of obstetric complications or poor pregnancy outcomes are at higher risk of maternal mortality.

Despite continued efforts, Pakistan is lagging behind in reaching the millennium development goals in maternal and neonatal health. ${ }^{2}$ The government is keen to improve maternal and infant health. Recently, there has been a shift in policy orientation toward reproductive health and safe motherhood at the federal and provincial levels.

Decentralization of power to the district level has provided a window of opportunity to improve the health system.

Historically, government health services in Pakistan have been comprised of fixed facilities that provide primarily curative care. Essential obstetric care (EOC) is available only in large city hospitals. Very few primary-level health facilities provide prenatal care or family planning. There is no system in place that provides information/education or counseling to expectant mothers.

\footnotetext{
${ }^{1}$ Throughout this document reference is made to various reports that together lay out in detail each aspect of the SMART project, from design to implementation to findings. This report describes the project interventions. For other aspects of the study, consult other SMART reports, which are listed at the beginning of this re port. ${ }^{2}$ Pakistan Millennium Development Goals Report 2005. (Millennium + 5 Summit.) September 2005. Planning Commission, Center for Research on Poverty Reduction and Income Distribution: Islamabad, Pakistan.
} 
Although the government introduced community-based lady health workers ${ }^{3}$ (LHWs) in 1994, they are not operational or effective in all areas. On paper, lady health workers are supposed to work in concert with traditional birth attendants, midwives or dais, and supervise deliveries; however, the reality is that the LHWs have no formal links with the traditional birth attendants. Nor do they have formal links with area health facilities. Given that traditional midwives conduct almost two-thirds of all deliveries in rural areas, and health facilities should be where complications in pregnancy/delivery are referred, the need for greater interaction is readily apparent.

An additional problem in health service delivery is that there is no community-based mechanism for monitoring the performance of government health facilities. Health personnel are not accountable to communities, who, in turn, have little interest or faith in the government health system. The Ministries of Health and Population Welfare are increasingly cooperating and integrating their services; however, duplication still occurs. The government realizes these shortcomings, and there have recently been efforts to integrate the field operations of these two ministries that are responsible for women's reproductive health needs. An ambitious national reproductive health services package is being promoted, with input from international and bilateral funding agencies. Implementation will be an uphill task in the absence of pilot operations research projects.

\section{DG Khan Context}

The district of DG Khan, where the SMART project was implemented, consists of hilly, rural terrain. The people who live there are predominantly part of a very poor and traditional society, relying on old, established customs. Men's decisionmaking dominates, within households and society. Overall literacy is low, and even lower among women. Only 18 percent of married women of reproductive age in the SMART baseline survey were literate.

Death rates of neonates and women during pregnancy, delivery and the postpartum period are high in this area. Social as well as medical causes were discussed during formative research conducted prior to the project, and studied more carefully in a verbal autopsy study.4 A major cause of death was found to be the lack of knowledge regarding the complications that may arise during pregnancy, delivery, and the postpartum period, as

\footnotetext{
${ }^{3} \mathrm{~A}$ short description of the history of the lady health worker program, and LHW requirements and responsibilities is available in the in-house addendum to this report, available on request from the Population Council.

${ }^{4}$ See SMART Report 5. Verbal Autopsies of Infant and Maternal Death and SMART Report 6. Formative Research on Maternal and Neonatal Health.
} 
well as those that can occur in a neonate. This lack of knowledge causes delays in seeking treatment for those complications. Public knowledge and attitudes towards issues regarding health are very poor in Pakistan, especially in areas such as DG Khan.

Access to mass media was obtained in the project household surveys. ${ }^{5}$ In the CBI area, approximately 19 percent of the population had access to television at baseline and 26 percent by the endline survey two years later. Similar proportions were obtained in the other areas, with significant increases between baseline and endline. Radio was less widely used, and readership of print media was very low. Therefore, it was evident that mass media may have been reaching a portion of the population in DG Khan, but it would not be the most effective tool of communication.

Ethnicity can also have strong effects on health-seeking behavior. Using language as a marker for ethnicity, Seraiki speakers are a substantial majority. In DG Khan, Baloch speakers, who have lived in the district for generations, tend to be an impoverished minority.

A wealth score was calculated based on the ownership of household assets and then this score was divided into quintiles. Balochi households were poorer, Punjabi households were richer, and Seraiki households fell in between. For example, 60 percent of Balochi, 52 percent Seraiki and 33 percent Punjabi households lie in the first two quintiles. It became evident that the approach adopted by the SMART project would have to be altered depending on the region or community where work was being undertaken.

From formative research, it became evident that many people's knowledge about the treatment of complications that may occur during pregnancy, delivery or the postpartum period was incorrect. Many families failed to seek any external treatment, and appeared to rely on home remedies and treatments, along with the assistance of midwives.

Due to the traditional structure of society, it is common for people to believe that illness occurs due to God's will, and the ill person would recover only when God wants them to. This is especially common when it comes to women's health, and less common in the event that a male or young child should fall ill. Women are seldom spared from housework, even when they are unwell. It was also reported that men in the community do not take women's complaints seriously, and often assume that women are making up the symptoms. Therefore, women hesitate to disclose health problems to others due to embarrassment or fear, and will only do so in the later stages of illness. Even at that stage, however, home

\footnotetext{
${ }^{5}$ See SMART Report 3. Change in Knowledge and Behavior of Women and Families.
} 
remedies are used. It is only after these remedies fail to take effect that the woman is brought to a hospital.

\section{The Three Delays}

In addition to taking into consideration the physical context when developing the SMART project, careful consideration was given to the Three Delay Model. ${ }^{6}$ A key factor in decreasing maternal, perinatal and neonatal mortality and morbidity is improving emergency obstetric care. Once an obstetric emergency occurs, the danger for mother and baby increases with the passage of time until appropriate treatment is started. A vast majority of maternal deaths are attributed to delays in obtaining maternal care during obstetric emergencies.

\section{Figure 1. The three delays}

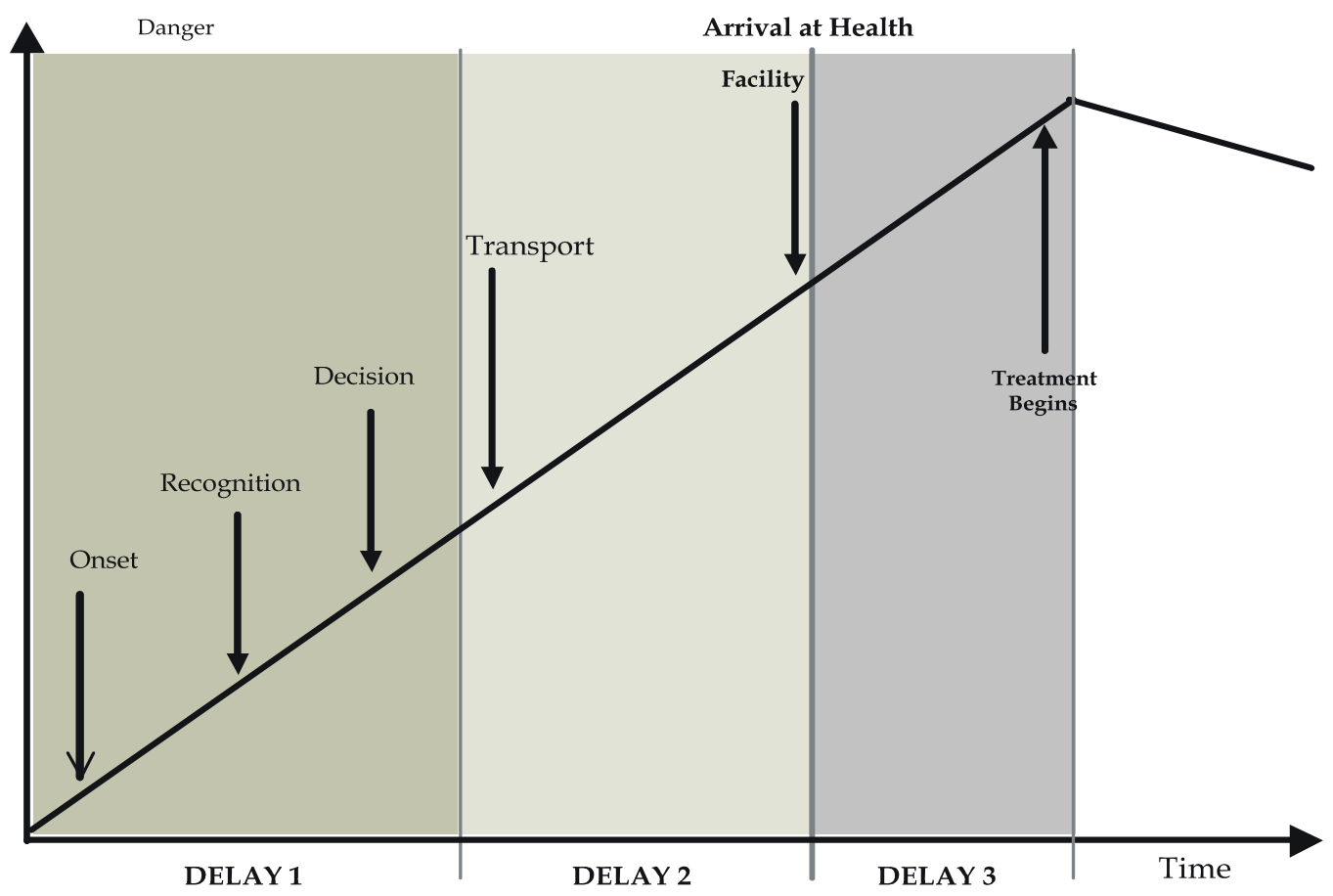

There are three delays that are encountered by women who are suffering from obstetric emergencies (see figure 1). The first occurs at home, and involves the decisionmaking process to determine if the woman should be taken to a medical facility. The delay is due in

\footnotetext{
${ }^{6}$ This model was used to develop previous interventions that the SMART project drew from; these are described below. The Three Delay Model was put forward by Thaddeus and Maine in 1994 (S. Thaddeus and D. Maine. 1994. Too far to walk: Maternal mortality in context. Social Science of Medicine 38 (May):1091-1110.
} 
part to household constraints that can largely be attributed to ignorance of the signs of impending complications on the part of expectant mothers, their families, and the birth attendants (usually a traditional midwife). Once the woman's family finally decides to seek treatment, the second delay is encountered: lack of appropriate and affordable transportation. Lack of proper and affordable transportation in most communities of Pakistan means that women are unable to go to a medical facility if an obstetric emergency occurs. Finally, the third delay occurs on arrival at a medical facility. The lack of properly trained medical staff, or unavailability of staff and proper equipment, often leaves women waiting for treatment.

\section{Previous Interventions}

Given the situation described above, the Pakistan and DG Khan context and the three delay model, the need to introduce interventions that would encourage and facilitate the use of reproductive health services seemed obvious. From this, the concept of community-based interventions in safe motherhood arose: interventions that would focus on raising community awareness of safe motherhood, while not overlooking the need to improve accessibility of reproductive health services and the quality of care provided there. If community awareness would increase demand, then facilities needed to be improved and upgraded to adequately respond.

SMART project staff looked first at what had already been done along these lines. Some innovative approaches to improving the quality of care within the district health system had been tested. A brief description of two of these innovative approaches follows.

\section{Client-Centered Approach ${ }^{7}$}

An operations research project using the client-centered approach to the delivery of reproductive health services was conducted by the Population Council from 1999 to 2002. ${ }^{8}$ This project was implemented in one tehsil (Bhalwal) of Sargodha district, in central Punjab. The intervention comprised of training health care providers of the health and population departments in the client-centered approach. The project was carried out through a six-day classroom training of the service providers at static clinics (DHQ, THQ, RHC, BHU and

\footnotetext{
${ }^{7}$ The client-centered approach is described in more detail in a box at the start of section 2 of this report; see also appendix 1 , which presents specific content of CCA training.

${ }^{8}$ See: S. Rao and A. M. Mir. 2004. Transforming Relationships in pakistani Villages. Quality/Calidad/Qualite No. 15.
} 
FWC) and in the community (LHWs and VBFPWs)..$^{9}$ The primary thrust of this interactive training was on changing the behavior of service providers toward their clients by improving their interpersonal skills. Results of this project showed a positive change.

From this work, the Population Council developed expertise in training in the clientcentered approach. In February 2005, the Council published an international-standard manual for trainers: A Client-Centered Approach to Reproductive Health: A Trainer's Manual.

The Population Council then used the client-centered approach in five additional districts under a project funded by the United Nations Population Fund (UNFPA). Again, the project showed positive results.

\section{Training Health Care Providers and Community Mobilization}

Another operations research project was implemented by the Asia Foundation, with the financial assistance of the Asian Development Bank (ADB), in Khuzdar, Balochistan (Pakistan). In this project, Balochistan Safe Motherhood Initiative-BSMI, the core intervention involved (1) training health care providers in emergency obstetric care (basic and comprehensive) and (2) community mobilization. This project used the Three Delay Model as the guide to where and what kind of interventions might be most effective in reducing maternal and neonatal deaths. The findings of this project were utilized in developing the SMART interventions.

\section{SMART Project}

In 2002, the Population Council designed a safe motherhood operations research project drawing from the successes and lessons learned from the projects described above, along with improved strategies to implement and test the effectiveness of proposed safe motherhood interventions. This project, Safe Motherhood Applied Research and Training, referred to as the SMART project, funded by the European Union, began implementation in October 2003 and ended in October 2006. The SMART project addressed all three of the delays described above. The first two delays were addressed through community-based interventions (CBI), while the third delay was addressed through health services interventions (HSI).

\footnotetext{
${ }^{9} \mathrm{DHQ}=$ district headquarters hospital; $\mathrm{THQ}=$ tehsil headquarters hospital; $\mathrm{RHC}=$ rural health center; $\mathrm{BHU}=$ basic health unit; FWC = family welfare centers; VBFPWs = village based family planning workers (the Ministry of Population Welfare's VBFPWs preceded the Ministry of Health's LHWs).
} 
The term safe motherhood refers to a woman's ability to have a safe and healthy pregnancy and delivery. The goal of safe motherhood can only be achieved by providing high-quality maternal health services to all women. The services essential to safe motherhood include prenatal care, safe and clean delivery, postpartum care, family planning, emergency obstetric care, and IEC for women, their families and the community at large. Achieving safe motherhood was the goal of the SMART project and all of the interventions were designed to work in concert to reach this goal.

\section{Study Design}

The SMART project was implemented as an operations research study to test the hypothesis that reducing all three delays, through the concerted efforts of a combination of communitybased interventions (CBI) and health systems interventions (HSI), would be significantly more effective than reducing the third delay alone through HSI.

The interventions described in this report were put into operation in the district of Dera Ghazi Khan (DG Khan), in southern Punjab province, Pakistan. The comparable, adjacent district of Layyah served as the control area. Details of the districts, site selection considerations, and population selection methodology are part of the overview of the SMART project. ${ }^{10}$

In rural DG Khan and Taunsa tehsils, 120 clusters (mouzas), each having an average population of 5,400 (about 590 households), were randomly selected, ${ }^{11}$ while 60 clusters were identified in Layyah. Once the clusters were selected, they were then divided into Site 1 and Site 2, where different intervention strategies would be implemented, and Site 3 (Layyah: the control site), where no intervention would take place:

- Site 1: 60 clusters for health services and community-based interventions $(C B I+H S I)$

- Site 2: 60 clusters for health services interventions only (HSI only)

- Site 3: 60 clusters for no interventions

A factor in cluster selection was the availability of the District Headquarters Hospital (DHQ) in the tehsil of DG Khan, and the Tehsil Headquarters Hospital (THQ) in the tehsil of Taunsa (both located in the district of DG Khan).

\footnotetext{
${ }^{10}$ See SMART Report 1. Project Overview. As described in the description of the SMART project that precedes this section, other project components include a household surveys, health services assessment, formative research and verbal autopsies. Details of the design, implementation and findings of these components are to be found in the individual reports referenced at the start of this report.

${ }^{11}$ Not including the de-excluded (tribal area).
} 
A substantial evaluation component was implemented to measure relevant changes in all three sites. The baseline and follow-up surveys to determine the effectiveness of the SMART interventions are presented in SMART Report 3. Change in Knowledge and Behavior of Women and Families.

The SMART project interventions covered a range of activities centered on improving the capacity of the health care system (within established institutions and within communities) and mobilizing families and communities to increase the utilization of reproductive health services so that maternal and neonatal mortality and morbidity in the project implementation site of DG Khan would be reduced. While DG Khan was the focus of activities carried out under this project, the project was always expected to be a test case for carrying out these interventions in other areas of Pakistan, with the goal of reducing maternal and neonatal deaths nationwide.

In designing the SMART interventions, careful attention was paid to the needs of the largely rural environment with limited resources, poverty and cultural restrictions on women's decisionmaking authority and mobility. The resulting interventions fell within two broad categories: (1) community-based interventions (CBI) and (2) health services interventions (HSI). Figure 2 illustrates the activities within each type of intervention.

\section{Figure 2. Intervention activities: home to hospital}

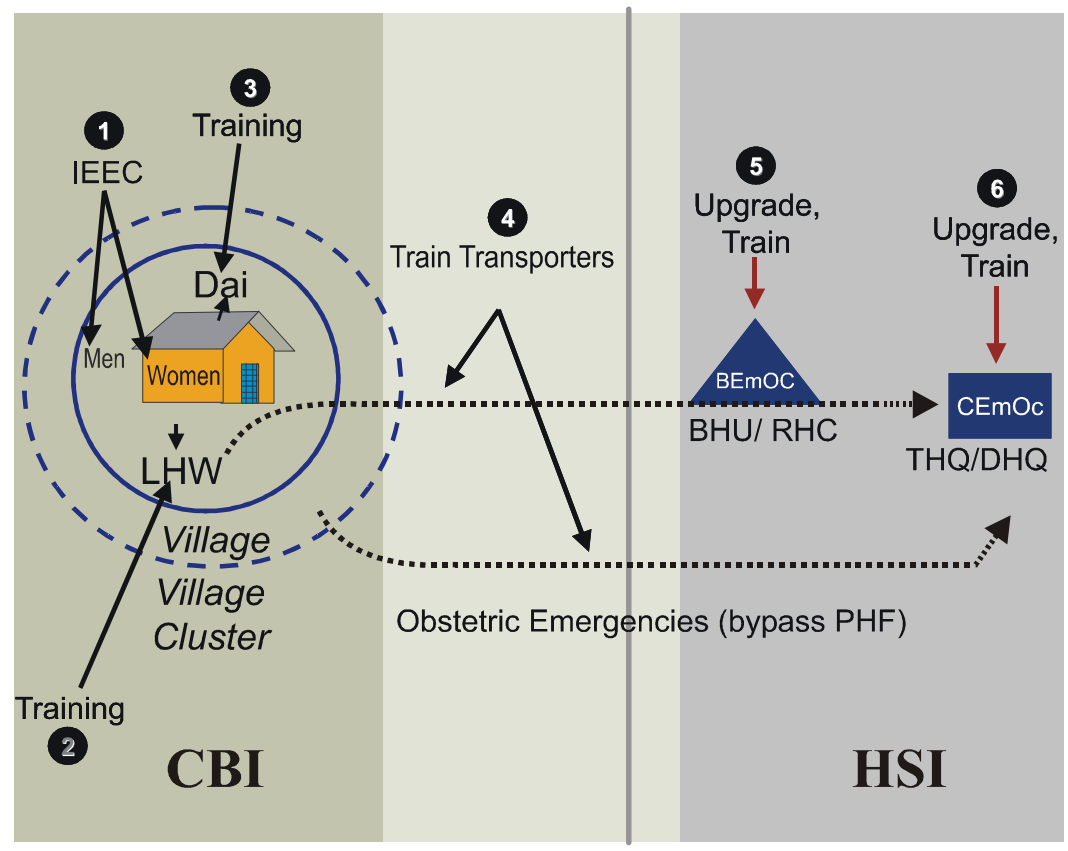
Delay 1
Delay 2
Delay 3 
Within the context of the Three Delays Model, community-based interventions were designed to prevent delays 1 and 2 -- that is, the delays that occur between the onset of an obstetrical emergency and arrival at a health facility. Prevention of delays in the model's third stage, between the point at which a woman arrives at a health facility and when she begins to receive appropriate medical care, were addressed through health services interventions.

The following is an outline of the interventions within each of the two broad categories:

\section{Community-based interventions}

A. Upgrading community-level health services by:

- Training lady health workers ${ }^{12}$ in:

- Client-centered approach to the provision of health services

- Basic emergency obstetric care (technical training in maternal and newborn care

- Training traditional birth attendants (called dais in Pakistan) in:

- Client-centered approach to the provision of health services

- Basic emergency obstetric care (technical training in maternal and newborn care

B. Educating and mobilizing communities ${ }^{13}$ to be more aware and knowledgeable about maternal and neonatal health issues by:

- Raising awareness at the micro-level of the problems and needs that arise during maternal and neonatal emergencies by:

- Creating support groups for all family and community members, with particular emphasis on men

- Developing information, education and communication materials (a long, involved separate activity but one that was fundamental to education, mobilization and raised awareness)

- Educating community leaders and community members about maternal and neonatal health

- Establishing village health committees

- Establishing a transport system for emergency obstetric and neonatal care cases

- Creating savings options so that funds are available when there is an obstetrical or neonatal emergency

- Establishing relations between communities and health facilities

\footnotetext{
12 The supervisors (LHSs) of the LHWs who were trained as part of the SMART project were included in the LHW training, both client-centered approach and technical training.

${ }^{13}$ Each of the intervention activities described below involved multiple steps, which are described under community mobilization.
} 
2. Health services interventions

A. Training health providers from the district health department ${ }^{14}$ and doctors in private practice ${ }^{15}$ in:

- Client-centered approach to the provision of health services (only for staff working with maternal and neonatal cases)

- Comprehensive emergency obstetric care

- Technical skills for maternal and neonatal care (basic emergency obstetric care)

B. Training managers of health and population welfare departments within public health facilities (static facilities) in:

- Client-centered approach to the provision of health services

- Leadership and supervision

\section{Presentation of Interventions in this Report}

The interventions are described in more detail in separate sections of this report. In the preceding outline, the interventions were presented under a site-based format (that is, within the formal public health services system or within the community-based formal and non-formal systems, as delineated by the SMART project). In this report, however, the interventions will be presented by type of activity, and then by whether they were community-based or health services interventions, as follows:

Section II. Training. All training activities are presented in this section. Community-based training interventions appear first, this includes training for lady health workers, dais, community members, community support group facilitators, and transporters). Descriptions of these trainings are followed by the health facility based interventions. This training included: doctors, paramedics, managers, and some doctors in private practice.

Section III. Community Mobilization and Education. Community mobilization and education activities come next. There is a separate section on the IEEC materials development and use because a significant amount of work went into their preparation and they were such an important part of all community mobilization and education activities.

\footnotetext{
${ }^{14}$ District health department provider's work at the district headquarters hospital, tehsil headquarters hospital, rural health centers, basic health units, or $\mathrm{MCH}$ Centers. Doctors and paramedics in the district health (including gynecologist, anesthetist, pediatrician, ward nurse, lady health visitor) are from all district health facilities; specialists mostly practice at the DHQ and THQ. The training of some doctors in private practice was a later addition to the project (see later description).

${ }^{15}$ Private practitioners were given only comprehensive EmOC training.
} 


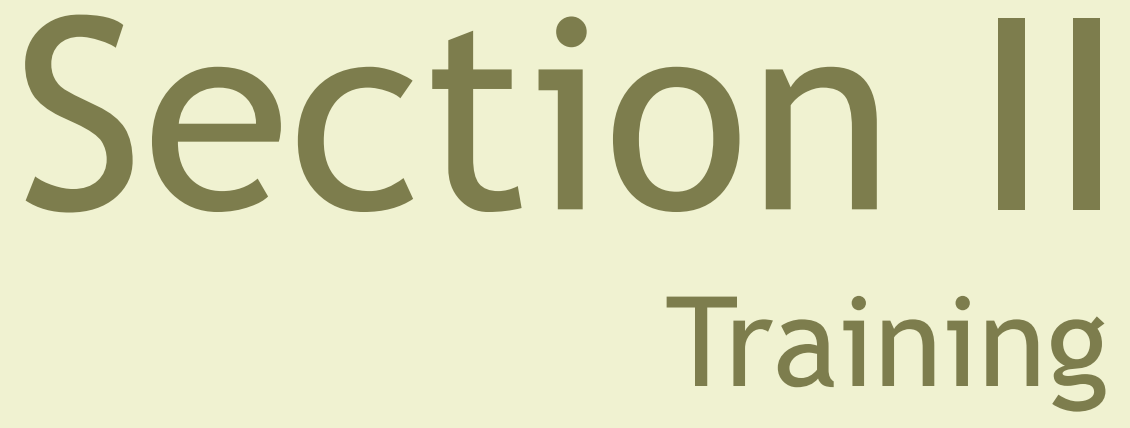





\section{Community-Based Training}

\section{Introduction}

Training community-level health care providers, both traditional birth attendants (dais) and lady health workers, was a major component of the community-based interventions designed to achieve the SMART goals.

To build capacity of the community-based health care providers in the intervention cluster areas, a training package was introduced for the LHWs and dais. This package consisted of two types of training: training in the client-centered approach and training on technical issues (basic maternal, neonatal and emergency obstetric care). Figure 3 illustrates the training for community-based service providers.

Figure 3. Training of community-based service providers

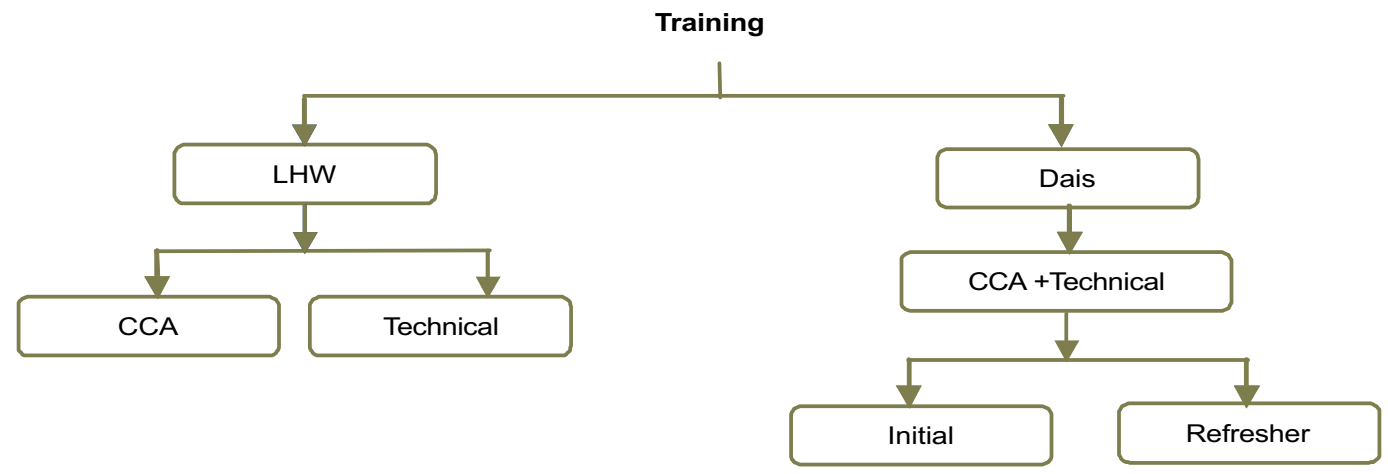

Following the description of the training given to the LHWs and dais, information is provided on other community-based training. This training was for community groups who received differing training according to their roles in SMART community-based activities. These individuals were village health committee members, support group facilitators, and transporters. All of these are part of the community-based interventions and had key roles in community mobilization. Only their training is described in this section; for a discussion of the important function each of these groups played in achieving SMART objectives, see section 3, on community mobilization. 


\section{What is the Client-Centered Approach?}

The client-centered approach (CCA) was central to the training given to all of the health care providers participating in the SMART interventions: both district public health service providers and community-based providers. It was hoped that this training would make a difference in maternal and neonatal care, resulting in lowering maternal and neonatal morbidity and mortality. More information on CCA course content is presented in appendix $1 .^{*}$

As described under previous interventions, the Population Council had already designed behavior-cum-communication training for health care providers, tested this approach, and published an international-standard manual for trainers, A Client-Centered Approach to Reproductive Health: A Trainer's Manual. This manual is used in all client-centered approach training. A copy is given to every person who takes the CCA training-of-trainers (TOT).

Quality of care is an essential part of the health delivery system. However, this does not refer only to the physical elements of care (e.g., building, supplies, etc.). The client-provider relationship itself is a key factor in quality of care. Any client entering a consultation room deserves due consideration from the provider. An aim of CCA is to allow clients to discuss their needs/circumstances freely and confidentially and to receive appropriate help and reassurance.

The atmosphere necessary for this to happen begins the moment clients enter a consultation room and are greeted in a friendly, respectful manner, and continues to appropriate care. To achieve client-centered service delivery requires a change in the behavior of service providers toward their clients. Improving providers' interpersonal communication skills is done in CCA using the acronym SAHR, which stands for Salutation, Assess, Help and Reassurance, representing the steps that providers should go through with each client.

The objective of CCA training within the SMART project was to use CCA, and SAHR, to bring about improvements in the clientprovider interaction. In addition, CCA training also addressed empowering clients through information exchange, and involving them in the choice of solutions available to them.

*A schedule for CCA training is included in an in-house addendum to this report, available on request from the Population Council. 


\section{Lady Health Workers ${ }^{16}$}

A total of 158 LHWs and LHS had CCA training; 170 LHWs and LHS had technical training. ${ }^{17}$

For training, Lady Health Workers were provided an opportunity to attend CCA training; then, after a couple of weeks, technical training was arranged. The purpose of this order of training was to first sensitize LHWs on the social issues related to the health of their clients, beyond the medical problems. ${ }^{18}$ At the start of the SMART project, there were 1,400 LHWs and 27 supervisors (LHS) in DG Khan providing coverage to about 40 percent of the population.

\section{Objectives}

LHW training was designed to improve the knowledge and practices of this group of community-based health providers. The following training objectives, the knowledge and skills that LHWs were to take away from the training, were to ensure that these improvements were achieved:

- Review and practice providing care and giving advice to women during antenatal and postnatal period

- Recognize the danger signs that occur during pregnancy, delivery and postpartum period, and know how to arrange timely referral to appropriate health facility

- Review and practically demonstrate the appropriate immediate care of newborns (warming, bathing, cleaning and cutting of cord)

- Practice giving advice to mothers on the importance of colostrums, breastfeeding and immunization

- Recognize the danger signs in a newborn, and know how to make refer to an appropriate health facility

- Resuscitate an asphyxiated neonate

- Develop liaison with dais of her area

\section{Client-Centered Approach Training}

Client-centered approach training for the lady health workers was almost identical to that

\footnotetext{
${ }^{16}$ All of the supervisors of the LHWs in the CBI intervention areas were included in training for LHWs.

${ }^{17}$ Of the 158 CCA trainees, 142 were LHWs and 16 were LHS (lady health worker supervisors). Of the 170 technical trainees, 156 were LHWs and 14 were LHS.

${ }^{18}$ An overview of the history, requirements and responsibilities of LHWs is included in an in -house addendum to this report, available on request from the Population Council.
} 
given to the doctors, paramedics and dais. Because much of the client-centered approach training relies on group interactive discussion, training content varied in terms of the specific settings/expectations that occur between provider groups and their clients. (See the box describing the client-centered approach; appendix 1 provides details on CCA training concepts.) The Population Council had done CCA training with lady health workers in the past and found them to be very receptive.

\section{Details of Training}

Trainers for LHW CCA training were trained along with the trainers for the doctor/paramedic training (for details on the training of trainers, see appendix 2).

LHWs who were from the community-based intervention areas were trained in eight batches. ${ }^{19}$ Training for LHWs began in August 2004 and continued at different intervals to April 2005. In Taunsa tehsil, all training activities were carried out at the THQ, while in DG Khan tehsil the training venues were BHUs and RHCs. The trainers for all CCA training used the Population Council's manual, A Client-Centered Approach to Reproductive Health: A Trainer's Manual (the content/concepts are outlined in appendix 1).

\section{Technical Training}

Although, all LHWs pass through a lengthy, comprehensive procedure during their 15-month training period, during formative research it was found that they needed refresher training on maternal and neonatal care issues. Therefore, a training curriculum specific to their needs was developed utilizing the formative research findings, existing curricula for community health care providers and observations of the formative research teams. An extensive effort went into developing the curricula.

\section{Details of Training}

The two teams of LHW trainers who had been fully involved in the formative research and development of the dai training package were the trainers. Two training-of-trainers workshops were arranged to impart

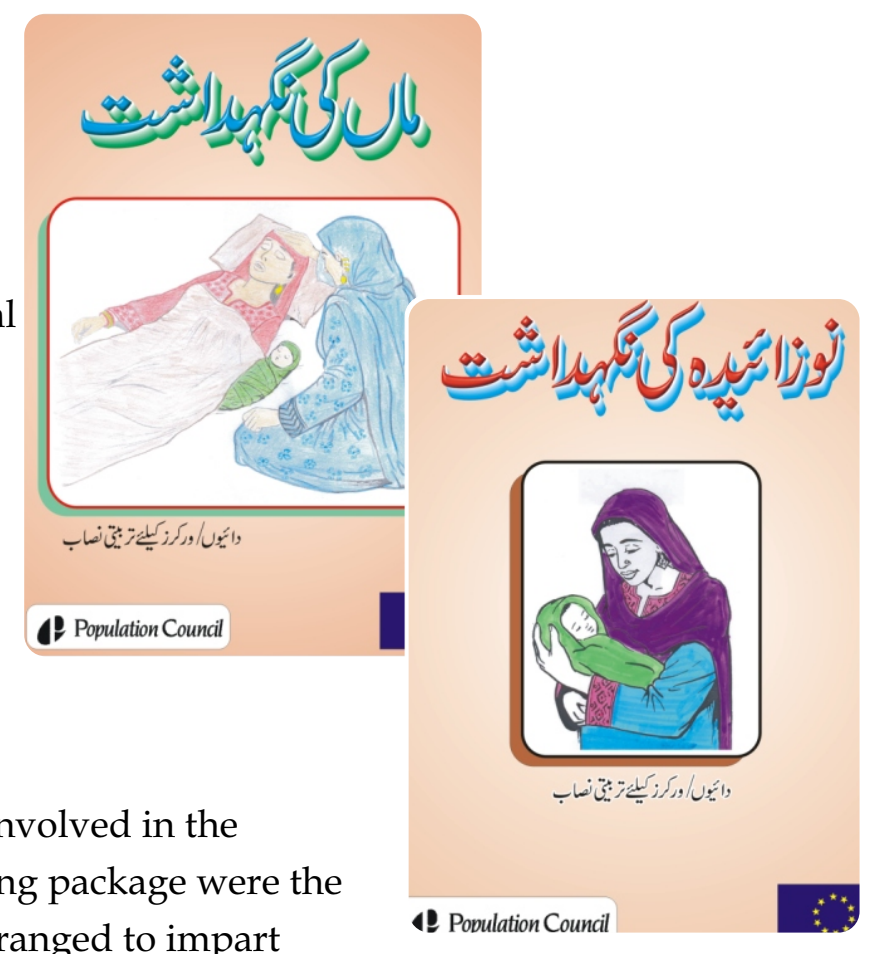
training on CCA, technical issues and teaching methodology. Training was done for those

\footnotetext{
${ }^{19} \mathrm{~A}$ list of those trained is included in an in-house addendum to this report, available on request from the Population Council.
} 
training LHWs and dais at the same time, from 6-11 August 2004, at the PC office in DG Khan.

There were 170 LHWs, including 14 supervisors, who were given MNH technical training. The participants accounted for nearly all of the LHWs in the CBI area. Eleven training sessions were arranged for LHWs; each session was seven days long. Training began in December 2004 and continued to May 2005, at different intervals. The sessions were arranged at health facilities: nine at RHCs, one session each at the BHU and THQ.

The methodology used was participatory: role-plays and case studies were utilized to clarify concepts and to develop analytical, decisionmaking and communication skills.

Demonstration techniques, using models, mannequins and dolls, were employed to develop practical skills for providing care to pregnant women and newborns. A video, Maan Aur Mamta, which had been developed by the National Committee on Maternal and Neonatal Health, was shown to participants to make them aware of complications that may occur in pregnancy, and the importance of timely referral to an appropriate facility.

\section{Follow-up Activity}

All LHWs were also visited again about six months after training. A questionnaire was given to each LHW to assess how much knowledge they had retained from the training. This questionnaire was also given to those LHWs who were not from the intervention area. This was done to determine the difference in knowledge between those who had received training and those who had not.

\section{Traditional Birth Attendants (Dais)}

A total of 288 dais were trained using a combination of CCA and technical training.

The first of the three delays occurs at the household level when either the families or the community health care providers, especially dais, are not able to recognize complications and refer clients with an obstetrical emergency to an appropriate health facility in a timely manner.

It is well documented that in rural areas dais are the key people responsible for assistance during pregnancies and deliveries. Therefore, pregnant women and their family members are dependant on the knowledge and skills of these community providers. Typically, dais do not receive formal training on maternal and neonatal care issues; they learn their skills 
by observing older women in the family, mothers or mothers-in-law, and then they begin to practice themselves. ${ }^{20}$ Unfortunately, much of the hands-on observation and learning includes unacceptable practices (e.g., frequent vaginal examinations, poor hygiene, etc.).

In addition to dangerous practices, dais have been very resistant when it comes to referring obstetrical emergencies at an early stage, even though they cannot manage the situation. One of the reasons for not referring obstetrical emergencies early is fear of losing the case, and the fee, and eventually losing their reputation in the community. So, referrals might only be made when the complication has progressed to a level where health-facility intervention, even at the district level, cannot save the woman's life.

Keeping in view what was known of the knowledge and practices of dais, the SMART project team working on community-based interventions devised a comprehensive training package that focused on enhancing the knowledge of dais on maternal and neonatal issues while also sensitizing them to the value of their clients, and responding to each client's needs and concerns. A description of dai training content is provided in appendix 3.

\section{Objectives}

To achieve improvements in the knowledge and practices of dais, the following objectives were developed:

- To refresh the knowledge of dais on maternal and neonatal issues, with a focus on the client-centered approach

- To introduce safe delivery practices and the use of the clean delivery kit

- To build a liaison between dais and LHWs

- To build a liaison between dais and health facilities

The last two items in the bulleted list above were added to the dai training curriculum because the existing relationship between dais and LHWs and between dais and health facility staff, especially those where dais could refer their clients, had not been as good or useful as it needed to be. This was a missed opportunity because these relationships were

\footnotetext{
${ }^{20}$ Note that there are two types of traditional birth attendants in Pakistan: those who receive formal training and work within the formal health services system and those living and working in their communities who may or may not have received specialized training. The term dai is used in this report to refer only to those TBAs who live and work in the communities where they live who may, or may not, have any degree of special training.
} 
important for better management of maternal and neonatal health care. During dai training, a session was arranged for dais and the LHWs who worked in their communities to meet and talk. They discussed their problems and concerns. The training team moderated this session. Through discussion and clarification, an effort was made to decrease the gap between the two groups so that they could work together cooperatively and effectively.

In the training session that brought together the dais and health facility staff, especially those involved in maternal and neonatal health care, the purpose was to bring together two extremes, both working for the health of mother and newborn. On one side were the dais working within the local community who needed the referral center, and on the other end were the facility-based doctors and paramedics who could provide advanced EmOC that was not possible to provide in community/home settings. There was a big gap between these two. The training team tried to reduce this gap, and lay the groundwork for better interaction and communication between the two.

\section{Development and Content of Dai Training Package}

Before training could be started, a training package had to be developed. Using extensive field activity to gain a stronger understanding of the knowledge, skills and practices of dais (and LHWs), formative research was done through nine focus group discussions and seven in-depth interviews conducted over a period of three months (See SMART Report 6. Formative Research on Maternal and Neonatal Health).

The materials prepared for the SMART Dai Training Package were: training brochure, trainers' manual (Maternal and Neonatal Health through Client-Centered Approach: Trainers' Manual for Dais [English translation]), a pictorial booklet, training charts and training video and CD. These are described below.

Dai training brochure. An eight-page brochure was developed that gives an overview of the training; it is basically a summary of the training package that provides a good reminder/review of training topics.

\section{Dai trainers' manual. A full-time consultant was} hired to develop the Dai Trainers' Manual. Training material were developed based on observations of the qualitative research teams and findings from the group discussions. All curricula on dai training available

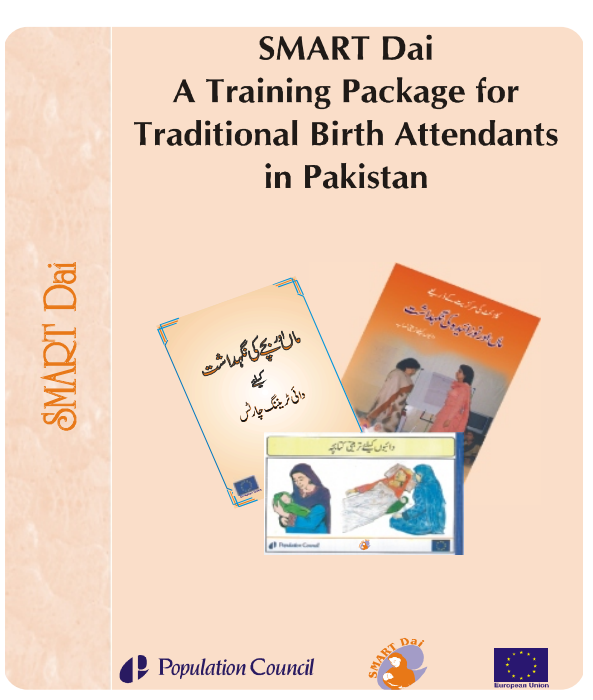




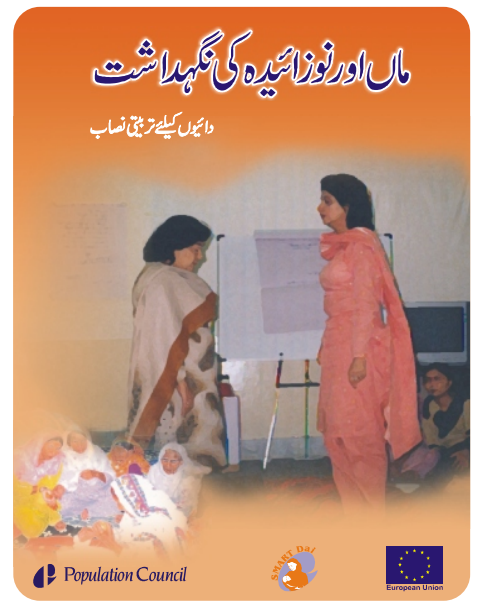

from various organizations at that time were reviewed. ${ }^{21}$ The Dai Trainers' Manual includes training in the client-centered approach and in basic EmOC technical areas, as shown below:

1. Client-centered approach. ${ }^{22}$ The following list is a good indication of the type of concepts and tools the dais take away from CCA training: ideal dai, self-awareness, gender, behavior, communication, and power.

2. Technical topics. ${ }^{23}$ The following is a list of fundamental basic EmOC topics covered: reproductive system, antenatal care, delivery (including clean delivery kit and money and transport), postnatal care, and neonatal care.

Dai training charts. During training sessions, the participants brainstorm in small groups on various issues. As almost all of the participants were illiterate, the team of trainers assisted them during the discussions. Issues were noted down on charts and then brought to the larger group for discussion. One set of these charts, as a reference, was available in the training package.

Dai pictorial booklet. Because of the problem with illiteracy, the team of trainers developed a booklet using illustrations to remind dais of important messages and obstetrical neonatal
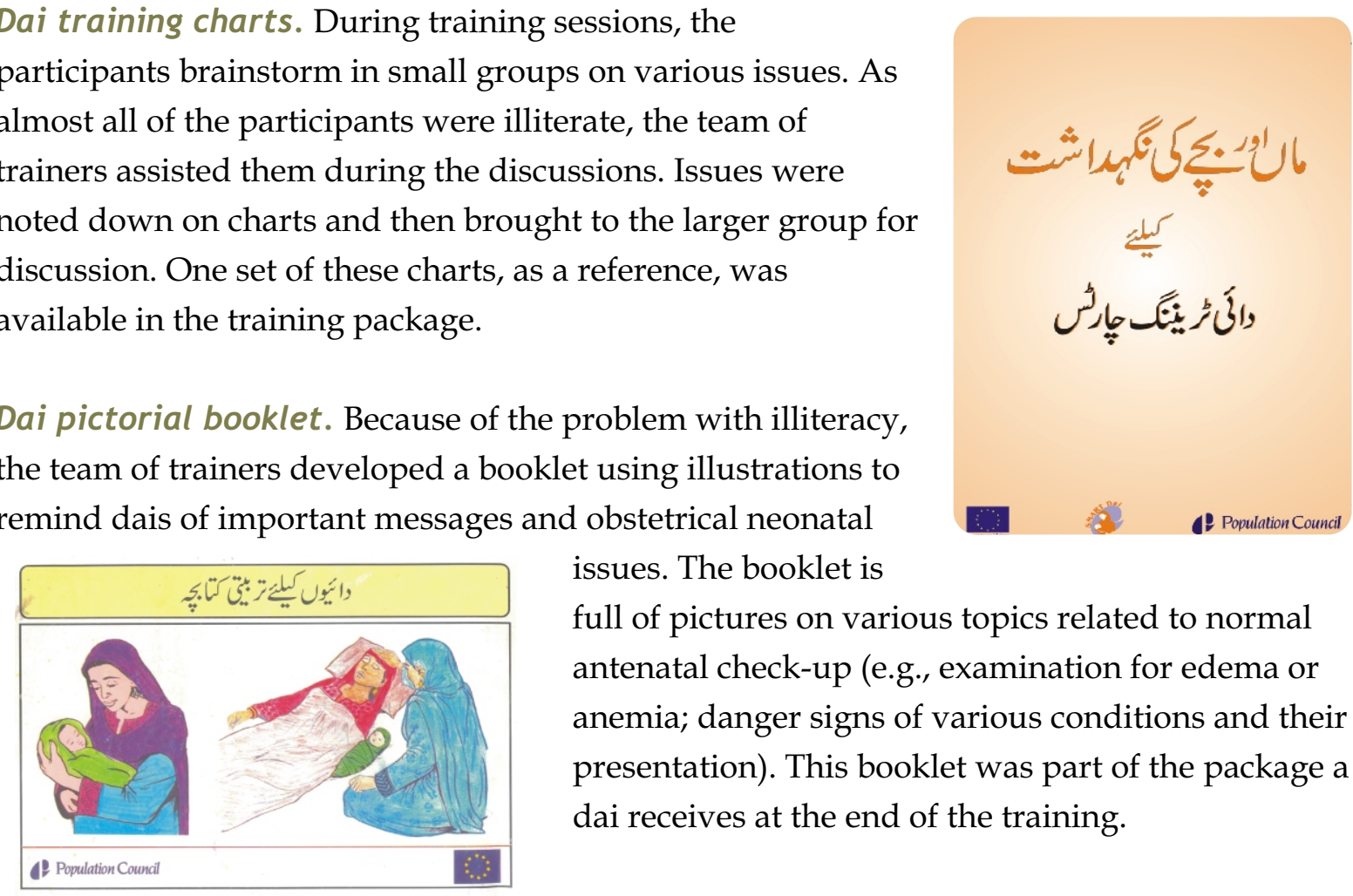
issues. The booklet is full of pictures on various topics related to normal antenatal check-up (e.g., examination for edema or anemia; danger signs of various conditions and their presentation). This booklet was part of the package a dai receives at the end of the training.

\footnotetext{
${ }^{21}$ Asia Foundation (Man aur mamta rahai salamat), Aga Khan University (Daion ki tarbiat ka nayya program), Provincial Health Development Center (Sindh), Save the Children (Clean delivery practices) US, CIDA and UNICEF (Daion ka tarbiati course).

${ }^{22}$ Because of the importance of the client-centered approach to the SMART project training interventions, both $\mathrm{CBI}$ and $\mathrm{HSI}$, this approach is described in a box at the start of this section; a brief description of CCA training concepts/content is provided in appendix 1. Information on CCA training specific to dais is provided in appendix 3.

${ }^{23}$ Appendix 3 includes details on dai training in technical topics.
} 
Dai video/CD. All training sessions were saved in a video. This works as a reference and can be utilized during training for demonstration of various practical steps (e.g., mouth-tomouth breathing in birth asphyxia in newborn, etc.). In future, this will be utilized to help new trainers.

\section{Selection of Dais}

Selection of an eligible dai was an important and time-consuming job. The SMART project team worked hard for three months to prepare a list of around 900 dais working in the 60 clusters of the community-based intervention component of the project. Out of these 900 dais, 300 were selected, based on established criteria, as follows:

- Active and busy dai in her community (e.g., conducting at least 3-5 deliveries per month)

- $\quad$ Age preferably below 60

- Accepted by the community in which she lived and worked

- Willing to participate in the training activity

After selection, these dais were invited to participate through a written invitation letter. Those who agreed were provided with pick-up and return service between their residence and the training venue. Arrangements were made for refreshments and tea. Dais who participated were paid Rs. 100/day to compensate them for the time spent in training and away from their practice.

\section{Training Details}

Training of dai trainers began after the preparation of the training package. Two training teams were established, each with a lady health visitor (LHV), two social workers and a senior trainer from Population Council. These teams had been fully involved in the formative research and development of the das training package. Two different training-oftrainers workshops were arranged to impart training on CCA, technical issues and teaching methodologies to be used. Training of dai trainers took place with the LHW trainers, from 611 August 2004, at the PC office in DG Khan. Once the teams were ready to start the training activities, they selected the eligible dais.

Training for dais included work on both the client-centered approach and technical topic(s), 
instead of having these broken into two separate trainings. The training used a combination of teaching methodologies. Dais already had a fair amount of knowledge on the training topics, but they were not performing according to that knowledge, or the knowledge was not correct, and they carried on dangerous practices. The training used different methods to get across the messages regarding proper knowledge and practices keeping in mind the sensitivities, and position within their communities, that these women had. A combination of the following methods proved useful: brainstorming, discussions, lectures, practical demonstrations, role-plays, and charts.

As compared to the curriculum, methodology and other ingredients of training sessions carried out in the past in Pakistan, this training had some very unique features, which worked in the direction of changing the attitude and behavior of the dais toward their clients. But before that behavior change the participants of the training were provided an environment with full respect, friendly and encouraging and participatory, which gave them an opportunity to share their experiences. This sharing of experience provided trainers with important insight into the dais' skill level and the severity of the dangerous practices they were using.

Dai training started on 23 August 2004 and continued through 31 May 2005. Training took place at area BHUs, RHCs and the PC staff house in DG Khan. Training was done in twentyseven batches, with ten to twelve dais in each batch; each batch trained for eight days. ${ }^{24} \mathrm{At}$ the completion of the training sessions, the participants were presented with a certificate of attendance, a set of five safe delivery kits, a group photograph and an honorarium.

\section{Follow-up Training}

To be sure that changes in behavior and practice due to the training had taken place, all trained dais were visited at least 4-6 months after their training to assess how much knowledge they had retained and what aspect of training they were using and what problems they were having. Results from this follow up indicated that dias needed additional training in some areas. Two days of refresher training was given to all available dias. Two teams of two LHVs each, who had been involved in initial training, conducted the refresher training.

\footnotetext{
${ }^{24} \mathrm{~A}$ list of those trained is included in an in-house addendum to this report, available on request from the Population Council.
} 


\section{Training Community Members ${ }^{25}$}

In the community meetings organized as part of raising community awareness, mobilization and education intervention efforts, described in the next section, three groups of individuals were given training to help them achieve the SMART goals within their communities. These groups are described below.

\section{Village health committee members}

A total of 612 VHCs were formed (337 for men and 275 for women); all VHC members were given an orientation to SMART.

A one-day session was conducted for the VHC members to orient them to SMART activities, the booklet and the cassette. Their responsibilities were discussed and they were also taught how to manage these activities. At the conclusion of their training, each VHC member received a phone
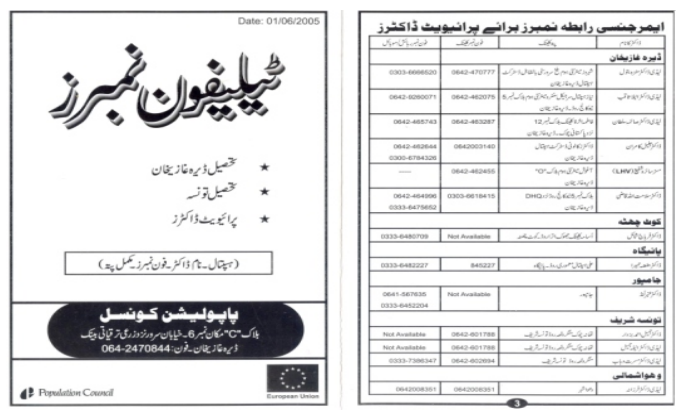
card that had the numbers and addresses they would need for emergencies. In this card, government and private doctors' home addresses, cell numbers and landline numbers were provided so that contact could be made quickly. This is important in an area where to this kind of information is extremely difficult to find.

\section{Support group facilitators}

A total of 2,332 facilitators (1,073 males and 1,259 females) were trained.

Support group facilitators were trained to conduct support groups using the booklet and cassette developed for this purpose in order to raise the awareness of community members regarding reproductive health issues. At the conclusion of their training, each facilitator also received a copy of the phone card given to VHC members, described above.

A three to four-day training was given to facilitators (males and females were trained separately) to enable them to conduct support group sessions using the cassette and booklet. During these sessions, some aspects of the client-centered approach were also discussed (e.g., gender issues, self-awareness, communication skills, etc.). Female support group facilitators practiced on a baby doll to learn proper techniques of newborn care (e.g., drying, warming, and resuscitating a baby). Role-plays were also conducted to demonstrate the

\footnotetext{
${ }^{25}$ All training materials mentioned below are described in section 3 (on IEEC) of this report.
} 
concept of the three delays and the community role in reducing them. Some difficulties that occurred when trying to train support group facilitators are described in section 3.

Note: all training materials mentioned in this discussion, are described in section 3 of this report (on IEEC).

\section{Drivers}

A total of 211 private transporters were trained.

In the community meeting, drivers and transporters were identified and sensitized to the various obstetric emergencies that can occur. This was done to ensure that they would volunteer their services to women who needed to reach a health facility in the event of an obstetric emergency. Once they were identified, a one-day orientation was given to them on the project, the three delays, and their role and importance in reducing the second delay. The transporters were sensitized to the problems faced by women, along with the importance of timely referral to an appropriate health facility for saving the lives of mothers and newborns. Their orientation also included developing liaisons with the staff of both public and private health facilities, which was done whenever the transporters had time. In addition to basic orientation to maternal and neonatal emergency needs, 168 transporters were helped to establish a relationship with public health facilities, and 142 transporters with private health facilities, so that when transporting clients, transporters would know where to go and who to contact. In addition, all drivers were given

\section{Follow-up Activity}

To assess the impact of community mobilization activities, and to ensure that support groups and transport systems were working properly, follow up was conducted. The team that had conducted the community mobilization activities also did the follow up as they could best assess changes in attitudes and behaviors of community members, and the functioning of the transport system. A total of 278 facilitators (111 males and 167 females) and 582 support group members (231 males and 351 females) were interviewed. In addition, about 10 focus group discussions were held with community members (separate groups for males and females), LHWs, and dais. 


\section{Facility-Based Training}

\section{Introduction}

As part of the baseline health services assessment, training needs and issues were identified. ${ }^{26}$ The groundwork for the training needs assessment was carried out from January to March 2004.

The health services interventions for medical personnel at the district public health facilities involved two types of training: training in the client-centered approach to the provision of reproductive health services and training in comprehensive or basic care for obstetric emergencies and maternal and neonatal care. (See figure 4.) For reasons described later, some private practice doctors were included in static facility training.

\section{Figure 4. Types of HSI trainings conducted}

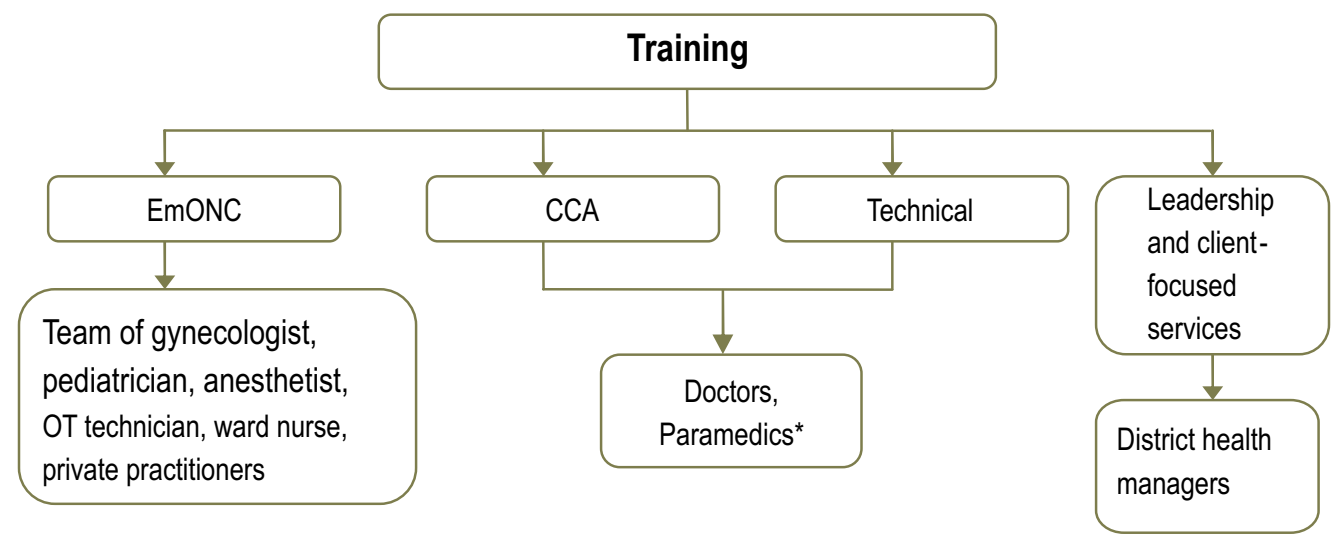

*Doctors and paramedics were from the RHCs, BHUs, MCH centers, or were on the staff of the DHQ and THQ, but were only staff members who dealt with maternal and neonatal health cases. Positions included: male and female doctors, LHVs, nurses, midwives, health technicians and dispensers.

Doctors and paramedics were trained in the client-centered approach to reproductive health to make their client contact more responsive to the needs of individual clients. They were given training in comprehensive emergency obstetric care so that they were fully prepared to respond to obstetric emergencies efficiently and appropriately. There was also training for managers within the health system; this training focused on leadership, supervision and client-centered service delivery.

\footnotetext{
${ }^{26}$ The baseline and endline needs assessments are presented in SMART Report 4. Knowledge and Behavior of Service Providers.
} 


\section{CCA Training for Doctors and Paramedics}

A total of 201 doctors and paramedics were trained.

Because of the importance of the client-centered approach to the SMART project training interventions, both CBI and HSI, a description of this training is provided at the start of this section; a short description of CCA concepts is included as appendix 1.

\section{Training Details}

The training of CCA trainers is described in appendix 2.

A listing of the those to be given CCA training was prepared with the help of Executive District Office (EDO) (Health). Trainees and their managers were contacted beforehand and informed about the training. A letter was sent to each participant, duly endorsed by the EDO office and the director of the District Health Development Center, to ensure that the participant would be available to attend the training. One of the teams trained in the clientcentered approach conducted the training.

Trainees, male and female, medical and paramedical, were all service providers from health facilities serving the population of the sampled cluster of the SMART project, who were providing consultative services to the clients of the district health facilities. Trainees came from the one District Headquarters Hospital (DHQ), the 1 Tehsil Headquarters Hospital (THQ), the 8 Rural Health Centers (RHCs), and the 35 Basic Health Centers (BHUs). Training was given to 58 medical officers, 17 women medical officers, 23 lady health visitors, 5 female medical technicians, 5 midwives, 6 family welfare workers, 4 nurses, 27 medical technicians, 55 dispensers, and 1 female assistant inspector-health. ${ }^{27}$ As for course content, see CCA description in an earlier box and the a general description of CCA concepts provided in appendix 1.

Training was done in nine batches; each training session was six days long, with the first beginning on 9 August 2004 and the last ending on 5 February 2005. Almost all trainings were held at the DHDC of the Health Department, DG Khan, but one was conducted at the training hall of the Population Council office in DG Khan and some were held at the THQ.

\footnotetext{
${ }^{27}$ A list of the names of the health facility doctors and paramedics who were trained in the client-centered approach is included in an in-house addendum to this report, available on request from the Population Council.
} 


\section{Comprehensive EmOC Training for Doctors and Paramedics}

A total of 8 doctors and paramedics were trained.

Training in comprehensive EmOC was designed to improve the capacity of doctors and paramedics at the DHQ and THQ to care for obstetric and neonatal emergencies. The need for this training was clear from the needs assessment of the public health facilities that was done at the start of the project. 28 The SMART project interventions would lead to an increase in patient use of the district and tehsil headquarters hospitals for emergency cases, so this training was seen as an important step in making sure that these medical referral sites would be fully prepared to meet patient needs.

\section{Training Details}

The primary person responsible for the comprehensive EmOC training was Dr. Ghazala Mehmood, Professor and Head of Obstetrics and Gynecology, Quaid-i-Azam Post Graduate Medical College, Pakistan Institute of Medicine, Islamabad. She prepared the materials and structured the sessions to meet the specific needs of the trainees.

The plan was to train two teams of doctors and paramedics (male and female) so that they would be fully prepared to handle emergencies. The teams were to include a gynecologist, anesthetist, pediatrician, operating room technician, and ward nurse. Though training was done for staff from the DHQ, there was a problem including staff from the THQ in Taunsa. At the THQ, there was no gynecologist, and not even one female doctor; therefore, it was not possible to put together a team that could provide emergency obstetric care. Although an anesthetist, pediatrician or operation theater technician can be male, it is only acceptable for a female service provider to provide immediate care for pregnant women, perform gynecological operations and conduct deliveries.

The first training, in March 2004 at PIMS, included a gynecologist, anesthetist, ward nurse and theatre technician from the DHQ; it was designed to meet the specific needs of this staff. A pediatrician was also invited, but he had already received similar training about a year before. After the first training, project staff realized that reliance on only public health facilities to handle referrals was not feasible due to the over-burdened and insufficient staff and facilities in the public sector. A decision was made to include gynecologists and pediatricians working in private hospitals providing emergency obstetric and neonatal care

${ }^{28}$ See SMART Report 4. Knowledge and Behavior of Service Providers. 
in the training. Therefore, the second training, at PIMS from 24-29 July 2005, was scheduled for four public doctors and four private doctors, but the public providers needed to attend to flood victims and were unable to participate. All training focused on the latest techniques in dealing with obstetric complications, including hands-on practice. ${ }^{29}$

\section{Technical Training (Basic EmOC) for Doctors and Paramedics}

A total of 104 doctors and paramedics were trained.

Technical training (basic EmOC) primarily involved updating clinical knowledge and skills in providing prenatal, natal and postnatal care, and identifying high-risk conditions. In addition, training included information on the latest interventions used for newborn care that would help reduce neonatal mortality and morbidity. Training was designed to improve the skills of health department staff and it was combined with CCA training in that only those who had participated in CCA training participated in the technical training. Unfortunately, not all district public health system service providers could be included in the training.

During the technical EmOC training, doctors and paramedics were in different training sessions. This was done so that different training needs of these groups of providers could be appropriately emphasized, even though the general course content was the same for each. The same procedures were followed for inviting the participants as was used for CCA training.

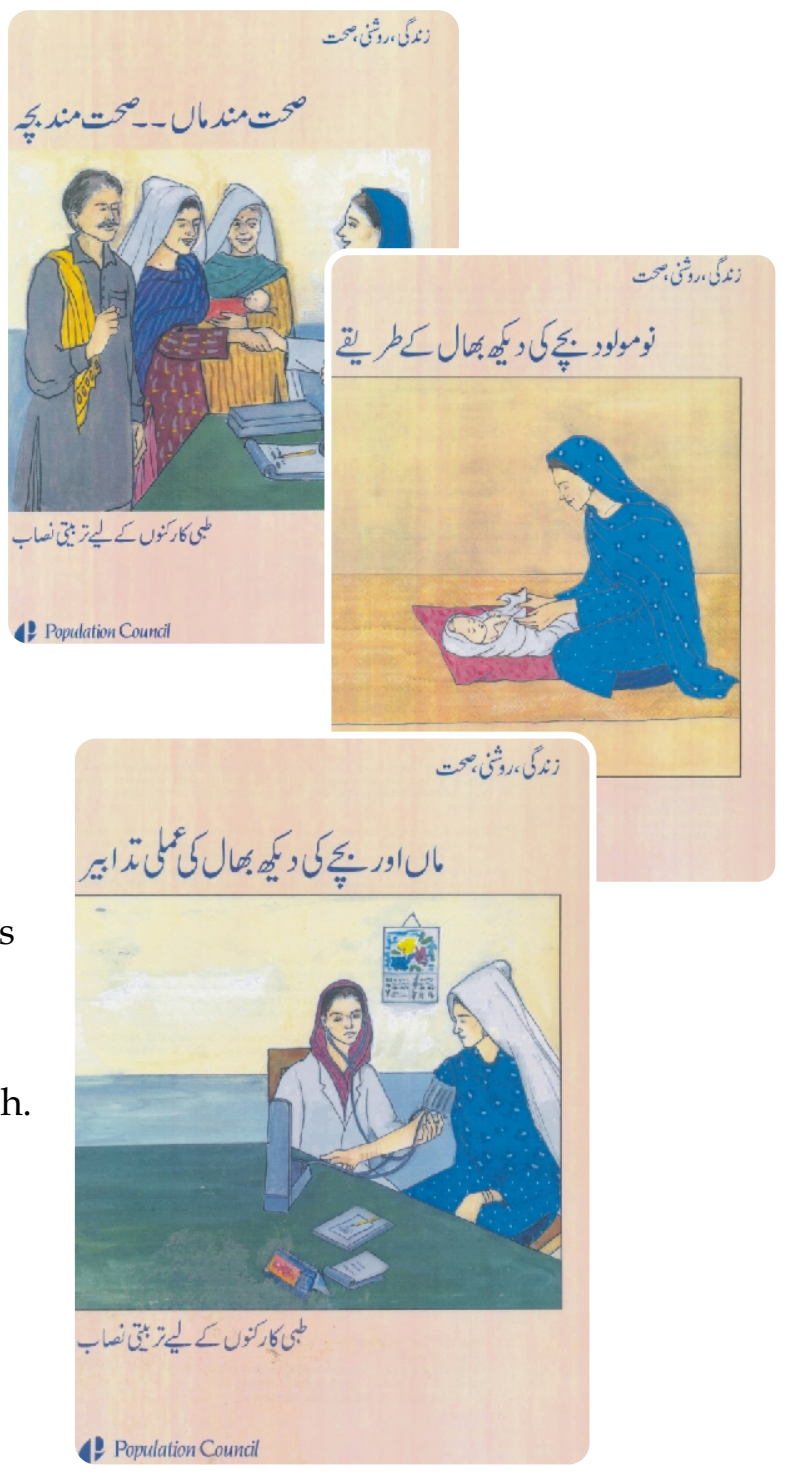

\footnotetext{
${ }^{29} \mathrm{~A}$ list of the doctors and paramedics who were trained is available in the in -house addendum to this report, available on request from the Population Council.
} 


\section{Training Details}

Training of the technical EmOC trainers was done by Dr. Farhana Zareef, who utilized manuals she had prepared for this purpose. Those selected to train as technical EmOC trainers were: gynecologists-2; lady doctors-2; paramedics, male and female-2. Training ran from 24-27 July 2004 at the Population Council's office in DG Khan.

Participants in the basic EmOC training were doctors and paramedic staff of the health department of DG Khan who had already received training in the client-centered approach to reproductive health. ${ }^{30}$ The topics covered in this training are outlined in appendix 4 . Basic EmOC/technical training was covered in a total of eleven batches in ten-day training sessions that ran from 13 September 2004 to 17 February 2005; the training took place in DG Khan. In addition to classroom training, participants visited different departments of the District Headquarters Hospital, especially the gynecology and pediatric wards, to become acquainted with the latest procedures being performed at that institution. Participants also visited the Reproductive Health Services Center (RHSC-A) set up by the Population Welfare Department, and the Marie Stopes clinic in order to familiarize themselves with services offered at these locations.

\section{Training District Health Managers}

A total of 13 managers were trained.

District health managers were trained through a workshop on Strengthening District Health Services Systems through Leadership and Client-Focused Services. Managers from different levels within the district health system attended the workshop. ${ }^{31}$ The workshop was held from 30 May 2005 to 3 June 2005 in Islamabad.

Effective district leadership means a clear vision for the district, focused toward reproductive health, and maternal and neonatal health, which is ready to change, accepts innovations, encourages intersectoral coordination, motivates, and provides better supervision to subordinates and facilitates provision of client-centered services to the people of the district. Therefore, the workshop for managers presented the following themes. Selfawareness is one of the basic leadership abilities. Effective leaders are aware of their leadership qualities, strengths, weaknesses, and on the basis of their knowledge they know

\footnotetext{
${ }^{30} \mathrm{~A}$ list of the names of doctors and paramedics who participated in the technical (Basic EmOC) training is included in an in-house addendum to this report, available on request from the Population Council.

${ }^{31} \mathrm{~A}$ list of district health managers who attended the workshop is included in an in-house addendum to this report, available on request from the Population Council.
} 
where, when and what type of team they need to establish to accomplish their vision. One of the main focuses of the workshop was to highlight leadership issues in the district. The discussion revolved around the role of the participants in better implementation of the program in the district. Participants were introduced to the client-centered approach to service delivery, and how it was linked to the quality and delivery of health care, and more specifically to reproductive health services. Managers also learned of the SAHR model for assessing and addressing the needs of the clients through a process of negotiation.

\section{Training Private Practitioners}

The health services intervention component was initially aimed at increasing the capacity of only public health facilities to function at an optimum level by ensuring that the skills and attitude of medical personnel who provide maternal and neonatal care was improved. Later in the project, however, the importance of involving private-sector service providers became clear to project staff. This was done to increase the scope of maternal and neonatal services because in the whole district there was only one public health facility, the DHQ, where emergencies could be treated (having the required gynecologist, anesthetist, blood transfusion and functioning operating theatre). Moreover, the Tehsil Headquarters Hospital, and many of the rural health centers and did not have a female service provider, rendering them non-functional on that basis as well, given that in more traditional areas, women may not be treated by a male doctor (for obstetrical/gynecological care).

A liaison was developed between the community and public and private practitioners. Seven private practitioners were selected from the district of DG Khan for training. Four were gynecologists and three were pediatricians. ${ }^{32}$ The four gynecologists attended additional EmOC training in Islamabad; two were from DG Khan and two were from Taunsa. 33 These private practice doctors were also asked to participate in a small community mobilization effort, described in section 3 .

\footnotetext{
32 Doctors in DG Khan were identified because the Population Council had worked with them; doctors in Taunsa were identified through the community and the staff of THQ.

${ }^{33}$ These four private practitioners are included in the total of the doctors and paramedics given comprehensive EmOC training (shown above).
} 


\section{Conclusion}

In the site where a substantial program of community interventions took place (CBI + HSI), the training of facilitators for support groups for women and men, transporters, local dais and lady health workers, appears to have had a strong positive impact. In this communitybased intervention site, perinatal mortality declined by about 22 percent, important though not quite statistically significant. This decline applied to both stillbirths and early neonatal deaths, and did not occur in the other two sites.

While it is difficult to separately evaluate the impact of the training of each of the cadres, it is apparent that particular components of the intervention are more likely to have a direct role in this decline. It is likely that an innovative program of dai training had an important effect. This training has been evaluated in an operations research project whose initial results appear to be very positive and enduring in terms of retention of the training content. Data show that the trained LHWs were more likely to have visited clients in their areas. The women's groups, especially when attended more than once, had an impact on reproductive knowledge. It appears that the training of various cadres in a multi-faceted communitybased intervention package can have a substantial independent impact on improving pregnancy and related outcomes, including perinatal mortality, in communities where they work.

In the HIS-only area, where facility-based training was the focus, little convincing change can be demonstrated in knowledge, practice, or mortality. It appears that in-service training of public sector providers had less of an effect on reducing perinatal mortality than the inputs in community-based interventions. The training of several hundred doctors and paramedics in both technical skills and client-centered counseling must necessarily have improved the quality of their services but not enough to have a substantial effect on outcomes in their areas. The conclusion from this effort is that a single round of training of facility-based personnel, including technical and client-centered care training, as well as management training of high-level personnel, is not sufficient in itself to make a significant difference on reducing perinatal mortality.

In conclusion, the training, while important, was not a sufficient input for strengthening facility-based care. Most definitely the training needs for such a comprehensive program must necessarily include wider improvements in emergency maternal and neonatal care at the health-facility level. Unfortunately, a wide reaching health services improvement program was outside the scope of this project. 
It is recommended that a full-fledged health services intervention must include repeated trainings and follow-up of facility staff. It must also include the training of health facility staff in the private sector, which in DG Khan provides most of the MNH services. Such a program, if successful, would be expected to have a strong synergistic interaction with a community-based intervention. 


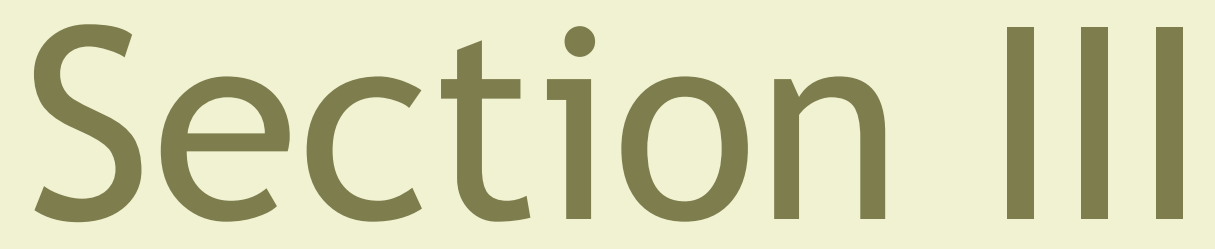

Community Mobilization and Education 



\section{Community Mobilization}

\section{Introduction}

Given the aim of the SMART project to reduce maternal, perinatal and neonatal mortality and morbidity through a combination of community-based and facility-based interventions, community mobilization was seen as an important ingredient in the mix of interventions, especially since it works both within the health delivery system and within and for the community. About 80 percent of the deliveries in rural Pakistan are conducted at home; out of these home-based deliveries, more than 80 percent are attended by dais (TBAs) or the family members/relatives of the pregnant women.

Most cases of maternal and early neonatal morbidity and mortality occur during these home deliveries. When complications occur during a home delivery, attendants may well not be able to recognize the severity of the complication, which can lead to difficult, and tragic, consequences. These unanticipated events are not expected by the birth attendants, whether a dai or relative, and they are ill-prepared to manage the needed decisions for transport to a medical facility. In a majority of cases, it is impossible to find proper transport given the bad roads, low ownership of automobiles, and a weak public transport system combined with a hilly terrain and large distances between villages. And then there is the problem of finding money to pay for transport and/or care. If a pregnant woman does make it to a referral facility, she may then find that providers and supplies are unavailable. Given the time issues that factor into emergency situations, the delays, as spelled out in the Three Delay Model, are costly in terms of life and health. In rural areas, particularly those more remote areas, maternal and neonatal emergency cases may end in serious problems or death, even though the case is treatable.

To address these problems, community mobilization and education were initiated. The SMART project objectives for community mobilization and education were:

1. To empower women to make decisions regarding their own reproductive health and choices, and to provide knowledge on safe motherhood issues, including nutrition, prenatal care, obstetric danger signs, safe delivery practices, family planning, and complications of induced abortions, so that they make informed decisions/choices.

2. To mobilize and organize community resources to facilitate better utilization of existing reproductive health services, particularly emergency obstetric care. 
The activities that were developed fell within the two general categories of (1) educating and mobilizing communities, ${ }^{34}$ and (2) raising community awareness. The Population Council conducted the community mobilization activities in 38 clusters through seven teams (each team comprised of two females and one male); while in 22 clusters the National Rural Support Program (NRSP) was working through two teams and their community workers.

\section{Mobilization Activities}

Mobilizing a rural community toward healthy practices, especially for the health of women during pregnancy, is a difficult task. A woman in a rural area is expected to carry out all of her normal household activities, even at the expense of her own health. When it comes to pregnancy, the issue is supposed to be managed only by the woman; there is no role for the men in her household, including her husband. A pregnant woman must not only shoulder her normal workload, but for help and advice, she can only rely on the older women in the household and community, including dais. For these reasons, efforts to mobilize communities, from individual households to the larger community, were important steps in achieving SMART goals.

In carrying out the community mobilization activities, there were six community mobilization component (CMC) teams each with one female supervisor, one female assistant supervisor, and one male mobilizer. There was an additional team for Balochi, which had only two female members. In addition, there was an overall male and female coordinator. Altogether, there were twenty-two members of the community mobilization component team.

Table 3.1 shows the impact that the specific community mobilization activities, described below, had on the SMART community-based intervention areas. The table also indicates the work done by the Population Council and that done by NRSP in carrying out the SMART community mobilization activities.

\section{Community-Level Interventions}

The first two delays of the Three Delay Model occur at the household and community level (recognizing complications and making the decision to get help from a higher-level facility,

\footnotetext{
${ }^{34}$ Community education, in this case specifically the development and use of IEEC materials, is presented separately in this section. It is important to note that community education was central to SMART project community mobilization efforts.
} 
and obtaining appropriate transport. Major activities carried out at the community level to decrease these two delays, within households and within communities, were:

- Mobilizing and organizing the community

- Establishing male and female health committees

- Establishing emergency obstetric and neonatal care funds (EmONC-F)

- Providing information and educational activities to make families and communities more aware of emergency obstetrics and neonatal care (EmONC)

- Establishing emergency obstetric and neonatal care transport systems (EmONC-TS)

One additional step that Population Council staff took, having realized the need to involve private practitioners in training, since the public sector was limited in providing adequate maternal and neonatal services, was to ask the private practice doctors to provide care to women and neonates, who were referred to them through Population Council trained dais and LHWs from the intervention area, on a priority basis, and to charge a subsidized fee. 


\section{Table 3.1 Community mobilization variables/activities completed by 31 August 2005}

\begin{tabular}{|c|c|c|c|}
\hline & Population & & \\
\hline Variables/activities & Council & NRSP $^{a}$ & Total \\
\hline Number of clusters & 38 & 22 & 60 \\
\hline Number of pockets & 778 & 617 & 1,395 \\
\hline Number of households & 18,260 & 16,183 & 34,443 \\
\hline Number of married women of reproductive age & 26,660 & 23,627 & 50,287 \\
\hline \multicolumn{4}{|l|}{ Number of village health committee participants } \\
\hline Male & 213 & 124 & 337 \\
\hline Female & 191 & 84 & 275 \\
\hline \multicolumn{4}{|l|}{ Number of facilitators trained } \\
\hline Male & 644 & 373 & 1,017 \\
\hline Female & 751 & 508 & 1,259 \\
\hline \multicolumn{4}{|l|}{ Number of support groups } \\
\hline Male & 620 & 364 & 984 \\
\hline Female & 1,573 & 628 & 2,201 \\
\hline \multicolumn{4}{|l|}{ Number of community members informed } \\
\hline Male & 6,452 & 4,862 & 11,314 \\
\hline Female & 15,275 & 6,456 & 21,731 \\
\hline Number of transporters trained & 128 & 83 & 211 \\
\hline Number of transporters linked with health facilities & 170 & 140 & 310 \\
\hline Number of health facilities where community liaison & & & \\
\hline developed & $20^{\mathrm{b}}$ & 0 & 20 \\
\hline $\begin{array}{l}\text { Number of village health committees linked with health } \\
\text { facilities in liaison process }\end{array}$ & $29^{c}$ & 3 & 32 \\
\hline
\end{tabular}

${ }^{\mathrm{a}}$ National Rural Support Program

${ }^{\mathrm{b}} \mathrm{DHQ}=1 ; \mathrm{THQ}=1 ; \mathrm{RHCs}=5 ; \mathrm{BHUs}=13$

${ }^{\mathrm{c}} \mathrm{DHQ}=3 ; \mathrm{THQ}=3 ; \mathrm{RHCs}=12 ; \mathrm{BHUs}=11$

The contribution of the National Rural Support Program to the following community-level activities was greatly appreciated, as they fulfilled their contractual role with due diligence. Their involvement was key to many of the steps that were required to carry out the activities listed above. There were essentially six steps to achieving the activities. These are described below.

\section{Step 1. Identification of local leaders ${ }^{35}$}

Leaders and key people at the community level strongly influence the lives of people in rural areas. When these leaders agree on an issue, then most of the time they create the will required for change to happen. These leaders were looked to as important catalysts in changing the practices of the people within project communities.

\footnotetext{
${ }^{35}$ The term influentials is often used to refer to those who hold some sway over public opinion and behavior; they may be either local or national leaders, or both.
} 
To identify community leaders, project staff organized seminars, which were attended by, apart from the federal, provincial and district officials of the departments of health and population welfare, the nazim, ${ }^{36}$ tehsil nazim and union council nazims of the districts. At these seminars, the SMART project was described, and the importance of community involvement, and the involvement of community leaders, was explained. A Population Council field team visited cluster areas and completed a questionnaire asking about local influential persons, LHWs, and the most popular dais of their area. They also tried to identify the mode of transport in the community that could be used at the time of an emergency, especially at night. From this information, a list of influential persons, both male and female, including dais, LHWs and drivers, was prepared. Community people willingly suggested the names of their local key leaders.

\section{Step 2. Meeting with local leaders}

After the identification of the leaders, the project teams set a meeting with them in order to introduce the project and give a brief description on the specific objectives of the project and their role in achieving those objectives, inviting the leaders to participate. A meeting with the community at large was then set, and leaders willing to participate were asked to arrange the meeting with about 60 to 70 percent of the community people. In most situations, leaders agreed to their role and to the meeting. On average, there were two to three leaders in each small locality in each cluster. If leaders successfully brought people to the meeting that was a strong indication that they were willing to cooperate, and the fact that people were willing to attend was an indication of the leader's leadership. Most of the time, project teams tried to have a meeting with the union council nazim of the respective cluster, councilors of that specific cluster and other key people.

\section{Step 3. Meeting with the community}

The identified leaders brought men and women to separate community meetings. At least one person from each household was invited to attend the meeting. After being introduced, the project team would then introduce the SMART project in a comprehensive way, focusing on the objectives and the role the communities could play in helping to achieve the SMART objectives. Staff introduced the village health committee concept as a way for the communities to be involved, noting that these committees would be responsible for ensuring that all project activities were carried out appropriately within the specified time. To facilitate the community in accessing health services, the SMART teams tried to develop

${ }^{36} \mathrm{~A}$ nazim is an elected district representative and heads the district government. 
liaisons between VHCs and the staff of health facilities.

Establishment of Village Health Committees (VHCs), including facilitators, emergency funds, cashiers and identification of transporters. At community meetings, the project team would ask for people to be involved in village health committee, and people would either volunteer or be nominated. This provided a good opportunity to discuss what the role of the facilitator of future support group sessions would be, as well as to discuss what the role of the cashiers would be in terms of the emergency obstetrical and neonatal fund (see below). In addition, transporters would either be identified, or health committees would be assigned the task of identifying them, so that they could be trained in how to provide transportation services in obstetric and neonatal emergencies. (See table 3.1.)

Communities had two options for dealing with their need for money for obstetrical or neonatal emergencies (referred to as the emergency obstetrical and neonatal fund (EmONCF). First, they could select a person who could deal with cash (a cashier) to whom households could regularly contribute (but only if they voluntarily did so) to the emergency obstetrical and neonatal fund. The cashier would maintain all records. In case of an emergency situation, funds would be utilized for needed services (normally transport or care). The community would decide how to use the funds: either all expenses would be met by the fund and the beneficiary would repay half of the expensed amount as one down payment after the emergency was resolved, or the beneficiary would pay in installments. A second option was to focus on the households in which pregnant women resided. All household members could contribute an amount on a weekly or monthly basis, whatever was feasible for them, to the fund within the household. These funds, saved over seven to eight months, would be utilized in case of an obstetric/neonatal emergency. Most communities preferred the second option.

\section{Step 4. Training for VHCs, support group facilitators and drivers}

It is important to remember that all village health committee members and facilitators were volunteers. A brief description of the training given to these groups of community members is provided in section 2 on training. Some problems in training support group facilitators are described under step 5, below. (See table 3.1.)

\section{Step 5. Support groups}

The use of support groups was primarily about raising community awareness, resulting in community mobilization. Both the Population Council and NRSP carried out activities 
designed to raise community awareness. At the family level, the focus was on husbands, women of reproductive age, mothers-in-law and traditional birth attendants. A separate formal training package was introduced for the capacity building of dais (see section 2, on dai training) since dais are an integral part of the community for maternal and neonatal health care. Table 3.1 shows the number of people who participated in support groups.

The facilitators, who had been identified at community meetings, moderated these support group activities, once they had been given training and orientation to group process (their training is described in section 2). Facilitators were responsible for conducting one or two support groups for members of their own communities; they were to identify ten to twelve community members for participation. Support groups were conducted separately for men and women in the intervention clusters. About six sessions (each one taking two to six days) were conducted depending on the availability of the group members.

Group sessions for women of reproductive ages were conducted in locations where there were about 20 women of reproductive age residing in households within close proximity to each other. The number of women closely matched a similar number of households. Twothirds of the pregnant women were motivated and invited to attend group sessions.

Since men tend to be at their work much of the time, it was difficult to involve them in group activities. However, they are comparatively more social, as they meet frequently, especially at night, and, thus, find opportunities to discuss and share various things. With this in mind, half of the men from each cluster were invited to attend group educational sessions. Because villagers have an active social life and community members intermingle quite regularly, sharing issues and concerns they have in common, it was hypothesized that other community members, men and women would receive the SMART information through diffusion from those who participated in group activities.

All group participants were provided with the booklet and the audiocassette prepared for support groups (Mothers and Motherhood Everlasting) (described later under IEEC) at the start of each group; each participant could keep a copy of the booklet and an audiocassette at the end of the sessions. The steps taken during the support groups are described in appendix 5. The support group facilitator would encourage those who were reluctant to accept the good practices that were brought up during the discussions; usually other group members joined in this positive reinforcement process. This is a process similar to that utilized to sensitize and raise awareness about various health problems (e.g., smokers who want to quit smoking, those suffering from chronic diseases). In such groups, peer pressure is an important tool in getting people to accept and follow information and instructions provided, 
and the SMART project strategy was to follow a similar logic.

Unfortunately, it was not possible to apply the same methods for gathering group participants in all clusters because of cultural differences, family feuds, residential status, caste systems, etc. Strategies were adapted to meet specific needs of particular groups and areas along the following lines:

Semi-urban areas: The men and women living in semi-urban areas were busy and did not have the time, or were unwilling, to sit in support groups or to act as facilitators. In these areas individual briefings were given. After identifying married women of reproductive ages, and the men, in each house, an introduction to the project was given and then booklets and cassettes were distributed and explained to each woman. The team then asked them to read the booklet and listen to the cassette. After about a week, they again visited the houses to confirm whether the cassette and/or booklet had been used. If they had, then an assessment was done regarding knowledge of the material. The team reinforced the weak areas and explained the material to the participant. If there was a LHW in the area, she was asked to supervise and do follow-up work.

Balochi areas: In Balochi areas, women are not allowed to go out of their houses, and often do not even visit houses in their own immediate area, mainly due to cultural reasons, but sometimes due to family feuds. Therefore, it was not possible to train facilitators in these areas. The Population Council team (a Baloch team) conducted all of the support groups. This was very time consuming.

Other areas: In some areas, due to the caste system, family feuds or religious barriers, people do not go to other pockets of the same cluster; hence, facilitator training was done for each small area. The number of facilitators was small (about five), so more trainings had to be conducted in each cluster.

\section{Step 6. Community and transporter relations with health facilities}

The necessity of helping communities and health facilities develop better working relationships was plainly evident. The doubts and fears of community members needed to be alleviated and health facility staff needed to be more aware and understanding of the problems being faced by the local people. The village health committees became the forum for discussions on how to increase utilization of the heath facilities. With the help of project staff, VHCs from 32 clusters were able to establish a relationship with health facilities. 
Liaison of 168 transporters with public health facilities, and 142 transporters with private health facilities, was established so that when transporting the clients, transporters would know where to go and who to contact. 


\section{Information and Education for Empowerment and Change (IEEC)}

\section{Introduction}

In designing the components of the community-based initiatives (CBI) package, SMART staff members realized the need for educational materials that were culturally appropriate and accessible to a predominantly non-literate population. Material was needed that could inform and educate people about how to reduce delays in treating complications faced during pregnancy, delivery and the postpartum period, for mothers as well as newborns.

A key component of the CBI package was to be a program of mothers' support groups that would meet for about six one-hour sessions to discuss maternal health. Thus, an essential requirement of the IEEC effort was to produce materials that could be effectively used in the context of these groups. (Ultimately, SMART staff decided to also hold husbands' support groups, and determined that with only minor changes the same materials could be used for both.)

It was believed that this information and education initiative would lead to a reduction in maternal and neonatal deaths. In planning the project and meeting with community members of DG Khan, it was also determined that such information and education would also empower the people of the area, especially women. To represent both the need for empowerment in this community and the empowering ability of information, this component of the community-based interventions was titled Information, Education and Empowerment for Change (IEEC).

To a substantial extent, the SMART project was explicitly modeled after the Balochistan Safe Motherhood Initiative (BSMI), which had similar aims and methods (see section 1). Hence the IEC materials developed for the BSMI project served as a starting point for the SMART project. These materials, as well as others developed by Save the Children USA (SC), were shared initially with members of the community in DG Khan. This was done to assess how the people of DG Khan received the various information, education and communication materials from other sources. The changes suggested by the community members were documented and utilized in the development of the SMART project's IEEC materials.

In addition, staff members from the BSMI Project also visited the SMART project to assist 
Population Council staff with the IEEC work, and to provide training for trainers. A weeklong training was held in DG Khan in May-June 2004, and community mobilization techniques were discussed. The BSMI teams shared the strategies they had employed when carrying out their project. Identification forms were created and were pre-tested in the district of DG Khan. Use of BSMI and SC materials in the development of the SMART project materials is described below.

The DG Khan context of the SMART project played an important role in the development of all IEEC materials (see section 1). Factors such as terrain, the traditional nature of the society there, male dominance in decisionmaking, low literacy, neonatal and maternal death rates, social attitudes toward pregnant women, lack of knowledge or incorrect knowledge of maternal and neonatal issues/care, minimal access to information through the media, and more, all played into decisions about how to determine what kinds of IEEC materials would have the greatest positive impact, and how to develop and distribute them.

For all of the reasons just cited, it was apparent that in addition to educating mothers, it would also be important to educate men, and to convince both men and women that women's health is important and that husbands and wives can work together throughout the cycle of childbirth to ensure the health and survival of both mothers and babies. IEEC materials were developed with these concerns in mind.

\section{Developing IEEC Materials}

The development of the IEEC materials involved a series of stages. First, formative research studies were undertaken, which were of value to the project design in general. Two of these studies were of particular value for IEEC development: a study of MNH terminology, and a study of knowledge and beliefs of women and men of reproductive age. While this report will present a brief outline of the formative research done on terminology and married women of reproductive age (MWRA), a more complete and comprehensive description of this research can be found in SMART Report 6. Formative Research: on Maternal and Neonatal Health. Second, field investigations were done to address particular issues related to the design of the IEEC component. Meanwhile, work on the design of the community mobilization component, in particular the women's and men's support groups, which the IEEC materials were designed to support, was carried out. Throughout the whole period details of overall project design were continuously discussed and refined. Third, a draft set of IEEC materials was prepared, pre-tested and then revised according to the pre-test results. Fourth, sufficient copies for initial use and review were produced, with time to revise for a second printing. Finally, sufficient copies for the entire project were printed. 
In all, three separate types of formative research were done in DG Khan for the SMART project. The first was formative research for terminology, which allowed SMART staff to ensure that all of the IEEC materials developed were culturally and linguistically sensitive to the area in which they were to be used. The second type of formative research involved qualitative research about the knowledge and attitudes of married women of reproductive age regarding maternal and neonatal health. The design and methodology of these are described below. The third type of formative research involved the knowledge and practice of dais, and is less relevant for this discussion of IEEC materials. The two types of formative research that were used in the development of IEEC materials are described below.

\section{Formative Research for Terminolo gy ${ }^{37}$}

Work on the formative research for terminology was conducted in October 2003, even before the project office was established. Male team members visited the lady health visitors at the basic health units, in both DG Khan and Layyah districts, to gather information about lady health workers in the villages. LHWs were then briefed about the SMART project and its major objectives; they assisted the team members in identifying and accessing women who fit the selection criteria.

The purpose of this sociocultural qualitative research was to gather information on Seraiki traditional vocabulary, specifically health-related terminology, and beliefs regarding maternal and neonatal care. Women were asked about their reproductive ages and their knowledge, attitude, and actions and concepts related to health problems during antenataldelivery-postpartum periods and neonatal care. Specifically, women's views about heavy bleeding, their perceptions of differences between bleeding before and after delivery, and their perceptions of the causes and consequences of complications during the childbearing cycle are solicited. Questions about how women respond or what they think should be done in the event of such complications were addressed.

Two basic methods were used for data collection: focus group discussions (FGDs) and structured in-depth interviews (IDIs). Areas of investigation included family planning, obstetric danger signs, high-risk pregnancy, anemia, food, local taboos, obstetric emergencies, antenatal care, care at delivery and postpartum, health services utilization, and attitude and behavior regarding neonatal care. Two sets of guidelines were developed: the first focused on pregnancy, delivery and postpartum issues, the second primarily on family

\footnotetext{
${ }^{37}$ A table of findings from the formative research on terminology is included as a table in an in-house addendum to this report, available on request from the Population Council. See also SMART Report 6. Formative Research on Maternal and Neonatal Health.
} 
planning. Questions on women's behavior regarding health service utilization were included in both. The guidelines were developed in a way that allowed the women to discuss problems they had experienced as well as problems they were aware of. If a woman had ever experienced a complication, she was encouraged to explain what happened; if she was aware of other women's experiences, she was encouraged to discuss these.

Twenty villages (ten in DG Khan and ten in Layyah), all within 15-25 km of the main city in the district, were selected as sites for FGDs, drawn by simple random sampling from the project mouzas. One FGD was selected from each of these twenty mouzas. For IDIs, MWRAs were selected from among participants sampled for the FGDs but unable to attend, and a local dai was interviewed, if available, also other providers were chosen from among project acquaintances in DG Khan town. The composition of the IDIs by type of participant and district is shown in table 3.1. Women who fit the selection criteria ${ }^{38}$ were recruited from each selected village in groups of 6-13 to participate in the FGDs. The only exceptions to these criteria were three lady health worker participants who were literate.

The 20 FGDs were conducted either at the home of the LHW or at a local school. All participants in the FGDs had similarly low levels of income. A total of 184 women participated in the FGDs: 87 from DG Khan and 97 from Layyah. Focus groups were divided into those for younger and older women (ages 15-33 and 31-49, respectively). All interviews were taped. One moderator/interviewer and one note-taker were assigned to each interview (focus-group discussions and in-depth interviews). The interviews were conducted in local languages (Seraiki, Balochi and Punjabi). The moderator for each FGD and IDI session completed a profile sheet, including the women's ages, total numbers of living children, duration of marriages, and women's and husbands' education and occupation. The note-taker took rough notes on the points and speakers; afterwards the note-taker wrote out the information and translated it into Urdu. (Later these were also transcribed into Seraiki to clarify terminology.) Finally, the transcripts were translated into English and entered as text into a computer. The English transcriptions were scrutinized to segregate key concepts to be used in IEEC development.

The information gathered from the focus group discussions and in-depth interviews was used to compile a list of frequently used terms describing obstetric complications and customs related to childbirth. 39

\footnotetext{
${ }^{38}$ Criteria: married, minimum of five children, illiterate, from the same community.

${ }^{39}$ The list of terms is included in an in-house addendum to this report, available on request from Population Council.
} 
Table 3.1. Numbers of focus group discussions and in-depth interviews for formative research on terminology, by area and participants

\begin{tabular}{lrrrrrr}
\hline & $\begin{array}{c}\text { Focus group } \\
\text { discussions } \\
\text { with women }\end{array}$ & $\begin{array}{r}\text { Married women of } \\
\text { reproductive ages }\end{array}$ & Doctors & LHVs & Dais & Midwives $^{\text {a }}$ \\
\hline DG Khan & 10 & 9 & 1 & 2 & 9 & 1 \\
Layyah & 10 & 6 & 0 & 3 & 1 & 0 \\
Total & 20 & $\mathbf{1 5}$ & $\mathbf{1}$ & $\mathbf{5}$ & $\mathbf{1 0}$ & $\mathbf{1}$ \\
\hline
\end{tabular}

${ }^{a}$ Midwives have one year of training and do deliveries.

\section{Formative Research for Knowledge and Attitudes of MWRA}

The other main source of formative research information for the IEEC materials involved FGDs and IDIs with married women of reproductive age. The objectives of this research were (1) to know the problems of ordinary women of reproductive age during pregnancy, delivery, and postpartum, and of neonates; (2) to know the health seeking behavior of MWRA in case of problems; and (3) to learn the perceptions of MWRA regarding dai skills and practice, in preparation for formative research on dais.

Guidelines were developed for the FGDs and IDIs to investigate specific topics within the major stages of the birth cycle, including family planning. Nine interviewers were selected and trained over 5 days. These were divided into 3 teams of two interviewers and one supervisor; two men were employed to arrange logistics. For FGDs, a note-taker assisted the moderator, while for IDIs the interviewer worked alone. Both types of interviews were tape recorded. From tapes and notes, an Urdu transcription was made. From these transcriptions a data matrix was made in English, with results of discussions on each topic summarized for each FGD or IDI. From this, results were analyzed..$^{40}$

Each district was divided into clusters, with five clusters selected at random from each district, and two villages from each cluster. Participants were selected with the help of LHWs and other local people. Eligible participants were currently married women aged 1549 with at least five living children, with the youngest child not less than five years old.

Table 3.2 shows the resulting sample.

\footnotetext{
${ }^{40}$ See the full report: SMART Report 6. Formative Research on Maternal and Neonatal Health.
} 
Table 3.2. Numbers of focus group discussions and in-depth interviews for formative research on knowledge and attitude of MWRA, by area and participants

\begin{tabular}{lrrr}
\hline District & Number of FGDs & Number of FGD & Number of IDI \\
participants & participants \\
\hline DG Khan & 10 & 94 & 26 \\
Layyah & 10 & 94 & 21 \\
Total & 20 & 188 & 47 \\
\hline
\end{tabular}

\section{Preparatory Fieldwork}

In January and February 2004, the IEEC team implemented a program of preparatory fieldwork toward the development of IEEC materials. The major objectives of this preparatory fieldwork were to assess: (1) LHWs, dais and other active women's ability to facilitate a group and motivate participation in discussion; (2) the amount of time that should be devoted to the discussion of each topic; (3) whether or not younger and older women should participate in separate support groups; (4) women's responses to using a booklet, (5) appropriate venues and times for the meetings; (6) the relationship between the size of the group and effectiveness of facilitation and level of attention of participants; (7) their interest in the concept of support groups; (8) interest and comprehension in audiorecorded script and messages; and (9) potential level of cooperation between LHWs, dais and women active in their communities.

For this preparatory fieldwork, the IEEC team conducted 42 female focus groups, with 294 married women of reproductive age, and 12 male focus groups, with 75 husbands, in the 15 rural communities of DG Khan (11 communities of tehsil DG Khan and 4 communities of tehsil Taunsa drawn at random from the 120 project communities in DG Khan district), along with 3 FGDs with lady health workers (LHWs) of these communities. The fieldwork was conducted in Seraiki, Balochi, or Urdu depending on the community involved. Upon completion of the fieldwork, an analysis was done on the FGDs using analytic matrices. (Appendix 6 shows the composition and topics of these focus groups.)

Four teams were established, each consisting of three members, a moderator and a notetaker for the FGDs and a "message person" working individually on audio scripts. The FGDs were primarily for the development of the IEEC booklet. The moderator would present a picture to the members of the focus group asking them to respond to the questions listed below. Their responses were recorded by the note-taker A total of four FGDs took place each day, led by a different team. Each group dealt with a separate topic: 
Team A: Discussed neonatal care, using only a discussion guide

Team B: Discussed the use of iron tablets during pregnancy, using materials from Save the Children USA

Team C: Discussed antenatal care, using the BSMI materials (currently pregnant women only)

Team D: Collected information on all three topics mentioned above from the male participants of the community

The facilitator asked each group to address the following questions:

1. What is happening in this picture?

2. What do you see in this picture?

3. What type of story is explained by these pictures?

4. Do you think you could use these pictures and messages to teach women in your community about this problem?

In addition to these discussion questions, a series of observational questions were used to assess the pre-testing sessions. These questions included:

1. What was easy and clear in the picture to you?

2. What was difficult for you to understand for the participants and why?

3. What did you like in the pictures?

4. What did you dislike in the pictures?

In the case of verbal messages, a message person, whose role was primarily to provide the basis for developing scripts for the audiocassettes, worked independently going from house to house meeting with individual women. She would play a recorded message to the woman she was interviewing, and would then discuss it with her. After the discussion she would ask the participant to repeat the message they had just discussed. This was done to determine how the people of DG Khan received verbal messages regarding maternal and neonatal health, and to ensure that the messages were well suited to the culture and tradition of the district. Feedback and suggestions were taken from the participants. 


\section{IEEC Booklet}

Designing the booklet. The IEEC booklet was central to IEEC support for the mothers' support groups. With the formative research completed, with the BSMI and other existing materials as guides, with general information on key social and health issues in DG Khan District, and with the preparatory fieldwork completed, the work of creating the IEEC materials began.

After the initial preparatory fieldwork, the changes suggested by the FGD participants were made, and a first draft of the SMART IEEC booklet was created. Important areas of change from the BSMI materials involved expansion of material on neonatal health and increased emphasis on empowerment of women and involvement of men. Messages were developed using local terms elicited in the terminology study and being

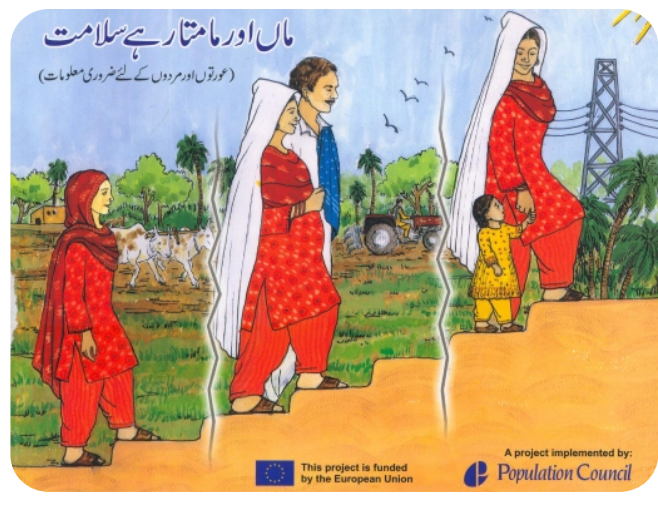
mindful of differences due to local traditions/culture. ${ }^{41}$ In this way the messages in the SMART IEEC booklet draft were altered to address the beliefs and practices in DG Khan. A rough script was prepared with messages adapted for the specific findings of this fieldwork, along with various local stories related to the messages.

A total of six focus group meetings were held to test the draft of the SMART IEEC booklet, and each focus group contained seven to twelve women. This pre-test occurred in May 2004. Women in each group explained their reactions to the booklet. Booklets were provided to all group members, and the following observations were made and questions were asked:

1. Which pictures needed improvement and why?

2. Were participants able to relate to the pictures for the entire story?

3. What was most difficult for the women in the process?

The following week, a team of two social mobilization staff from the BSMI project visited the SMART project to discuss the implementation of community mobilization generally, including IEEC. On this basis, a second pre-test was conducted on 5-11 June in eight clusters (six Seraiki and two Balochi clusters) in DG Khan. Subsequently, the revised draft booklet

\footnotetext{
${ }^{41}$ For example, for the BSMI Project, the word khayal meant bleeding; however, in DG Khan the phrase kaprey aana was used in the booklets. Also, the traditional taboos that the BSMI project dealt with were very different from those that were present in DG Khan. For example, in Balochi culture, potatoes were considered harmful during pregnancy. In DG Khan, however, lentils were considered harmful .
} 
and scripts (for audio) were shared for comment with Dr. Sadiqua Jafarey and Ms Imtiaz Kemal of the National Center for Maternal and Neonatal Health and other consultants. ${ }^{42}$

The title was given careful consideration. Different aspects were considered in the selection of the title, including the ease with which it could be understood and its link to the SMART project. The opinion of IEC experts was sought prior to the finalization of the title. The title was chosen due to the strong emotions it would potentially incite in mothers. Options for the title of the booklet included: Light (Ujala), Lessons of Life (Sabak zindage kay), and The Role of Women in Childcare (Bachay ki nigehdasht main maan ka kirdar). Finally, at the suggestion of the PC Islamabad staff and IEC experts, the title chosen was the same title used for the BSMI project booklet: Mothers and Motherhood Everlasting (Maan or Mamta Rahay Salamat). With the initial stages of preparation finished, and a title selected, the final version was ready.

Final version. The final booklet consisted of thirty-one colored pages, primarily pictorial but with some writing giving the key messages. Each of the seven chapters was assigned a different color (with a colored bar or stripe of that color across the top of all pages in that chapter). Each chapter was portrayed through a story of a particular woman, a point clarified and reinforced in the audiocassette. A brief overview of the topics covered in the booklet appears below; for a detailed description of each section of the booklet, see appendix 7 .

- Front page. The cover page of the booklet depicts the various stages of life a woman goes through.

- Chapters. There are seven chapters in the IEEC booklet, each containing a different message related to maternal and newborn health. The colors and names of chapters are: 1. Brown: Nutrition; 2. Dark blue: Antenatal care; 3. Red: Danger signs; 4. Pink: Safe delivery practices; 5 . Purple: Postpartum care; 6. Blue: Neonatal care; and 7. Green: Family planning methods.

- Back cover. A picture of a focus group discussion is on the back: it shows each woman has a copy of the IEEC booklet. An audiocassette player and a facilitator also appear.

\footnotetext{
${ }^{42}$ A detailed review of the changes made in the IEEC booklet as a result of pre-testing is included in an inhouse addendum to this report, available on request from the Population Council.
} 
Publication. Development of the initial draft of the booklet was done in conjunction with Crystal Printers, who hired an artist to visit DG Khan to understand the district visually. She was then given the scripts, and began preparation of the booklet. Sketches were colored in the field, with input from the staff and community members. Preparation was completed in Islamabad, in coordination with the IEEC coordinator, who came up to Islamabad for the purpose. This booklet was pre-tested as previously explained, and amendments determined.

Preparation of the revised draft for printing required about three weeks of intensive work among the printer, the artist, and the IEEC coordinator in Islamabad, which took place in June 2004. Approximately 12,000 booklets were printed by Crystal Printers in Islamabad in August 2004.

In February 2005, a second edition of the booklet was produced following some amendments and minor changes according to suggestions made by members of the community. Approximately 62,000 booklets were produced and printed once the second edition was finalized, of which 36,000 were the female version and 26,000 were designed for the men.

\section{IEEC Audiocassette}

Designing the audiocassette. Development of the audiocassettes paralleled the development of the booklet. The BSMI materials were once again used as the starting point to develop the audiocassette. The purpose of the audiocassette was to provide text by which a largely illiterate population could better understand the messages presented in pictorial form in the booklet. The audiocassette contained all the details and messages present in the booklet. Each of the seven sections (corresponding to the seven section of the booklet) was separated by clips of local music, denoting the end and beginning of each part. The name and number of each part is announced prior to the message. The script for each section follows actual stories collected from local women during the formative research. All of these stories were based on true incidents that occurred within those communities in which SMART was being implemented. However, all names were changed. Thus, people were able to identify with these stories much better than if they had been fictional, or from another locality.

The "message person" initially tried out possible messages during the preparatory fieldwork. Selection of the messages that would be included in the audiocassette were based 
on the level at which participants understood those messages. The messages that were widely and easily understood were kept and related to a story, while those that were not understood were altered to be more culturally and linguistically appropriate to DG Khan.

The stories to be used were developed in May 2004, at the same time as the draft booklet was being developed. An initial draft, recorded and pre-tested at the same time as the booklet, was shared with the BSMI team during their visit, and pre-tested again in early June. This time, men were also included in the pre-testing of these messages to ensure that both men and women would accept them. Based on the pre-testing and discussions, a new draft was prepared in Seraiki. This version was then compared with the draft booklet to ensure that the stories in the audiocassette were congruent with those in the booklet. After this testing, the audiocassette was shared with experts (as above) and finalized for production.

Final version. The audiocassette, lasting 1 hour, 20 minutes (female, Seraiki), combined the stories, presented in drama form, with the messages given in the booklet. (The only difference between the female and male versions is that the narrator is female for the female versions, male for the male versions.) Like the booklet, the cassette is divided into seven sections, separated by musical dividers. Within each section, the narrator introduces the section, followed by a segment of drama, a brief period of music, the narrator giving the messages illustrated by the segment, another brief period of music, another segment of drama, and so on to the end of the section. At the end of the cassette, a poem is read dedicated to mothers urging respect and care for them.

Although the pictures in the booklet illustrate the dramas, the cassette provides the complete story; the messages, however, are the same in each. The audiocassettes are available in Seraiki, Balochi and Urdu.

Production. The audiocassette was produced in the languages most frequently spoken in the district, Seraiki and Balochi. The Seraiki version of the audiocassette was recorded at the Radio Pakistan station in Multan. Major artists who took part in the recording were Mujtaba Alvee, Mazhar Ahsan, Bahar Hussain, Sadia Batool, Sahar Sial, Tasleem Mehboob and Farah Naz. Fakhar Baloch and Ashfa Hashmi also participated as guest artists. These artists recorded the stories, dramas and anchor voices according to the script.

Initially, the recording was made on spool tapes used at radio stations. The Sound Max company then completed digital recording at their private recording studio in Multan. In August, 300 initial copies were prepared for pre-testing in local areas. Sound Max then 
produced 10,000 copies of the audiocassette for both males and females. A second edition of the audiocassette was also produced along with the second edition of the booklet. The Balochi version of the audiocassette was produced at the radio station in Quetta. The Balochi artists involved in the recording process were Ms Ghulam Jan, Ms Effat and Quetta radio artists team. Sound Max Multan produced the Balochi cassettes.

At the demand of Urdu-speaking communities, mostly in semiurban areas, an Urdu language audiocassette was produced in January 2005. The script and material used for the Seraiki and Balochi versions were used. The community mobilization component team ${ }^{43}$ participated in the recording of the Urdu-language audiocassette. All of the characters were performed by the CMC team. The recording process was completed at the Sound Max studio in Multan.

Ultimately about 25,000 Seraiki language cassettes were produced $(15,000$ for women and 10,000 for men). For Balochi and Urdu, 2,000 of each were produced, of which 1,500 were for women.

\section{ANC Card}

Designing the card. The ANC pictorial card was designed for pregnant women to keep with them during their pregnancies as a reminder of what to do and what to watch out for. Materials borrowed from the BSMI project were used as the basis for the development of the card, and tested during the preparatory fieldwork.

The objectives of the ANC cards for pregnant women were to:

- Provide basic information to those pregnant women who would deliver before the start of the community mobilization work

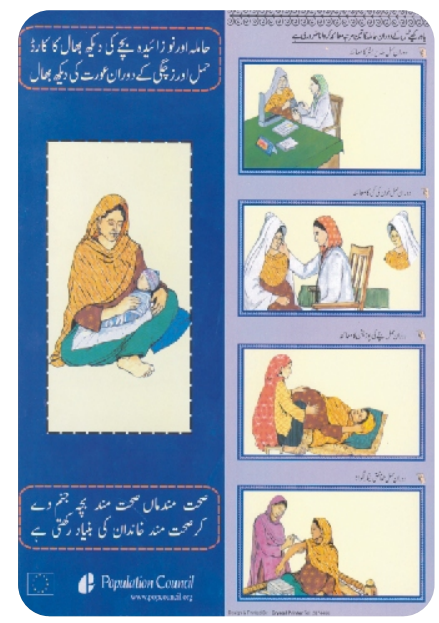

- Provide information about appropriate antenatal care (and TT shot), not only for women who have delivered but also neonates

- Increase routine check-ups

- Develop rapport between pregnant women and trained health providers

- Develop trend that pregnant women discuss every matter regarding pregnancy, delivery and postpartum period with her husband and other family members

\footnotetext{
${ }^{43}$ The 22 people who carried out community mobilization component (CMC) activities worked in teams, described in community mobilization at the start of this section.
} 
- Promote pregnant women's mobility

- Provide basic information about complications during pregnancy, delivery and postpartum period, and their treatment at household level

- Enable women to take better care of their newborns

The ANC card was derived from the booklet. In consultation with PC staff and the National Commission for Maternal and Neonatal Health (NCMNH), illustrations from the booklet were selected according to which particular topics and messages were to be emphasized. As with the development of the booklet, the ANC card was developed after gathering suggestions and feedback from the community of DG Khan based on the material taken from the BSMI project. The pictures were rated on level of importance, and incorrect practices and beliefs were noted. Based on this information, a draft of the ANC card was prepared.

The initial draft of the ANC card was then pre-tested in the community during the first pretest of materials in May 2004; changes were made according to the suggestions and feedback of participants. These changes were incorporated, and a final version of the ANC card was made.

Final version. The ANC care card is printed on stiff glossy paper, folded into 8 panels. After the cover panel, the ANC care card has a panel for each of the seven main topics of the booklet, with four pictures on each panel each of which illustrates a single message. The front page of the ANC care card shows a woman holding a newborn baby; the writing on this page says: A Card for Care of Pregnant Women and Neonates: Care of Women During Pregnancy and Delivery (English translation). At the bottom of the page it says: Healthy Mother Gives Birth to Health Child (English translation). The other panels of the card, each with four pictures, are as follows; more details are given in appendix 8 .

- Section 1: Routine antenatal check-up

- Section 2: Danger signs during pregnancy

- Section 3: Safe delivery practices and birth preparedness

- Section 4: Danger signs of delivery and postpartum, including family planning advice

- Section 5: Immediate newborn care

- Section 6: Postpartum care and danger signs

- Section 7: Early infant care

Publication. Council staff at PC/Islamabad formatted and prepared the card, which was sent to Crystal printers for printing in June 2004. Crystal Printers produced about 2,900 
cards in August 2004, while an additional 2,000 cards were produced in June 2005, as per requirement. In the nearly one year of community mobilization intervention work, approximately 4,600 cards were delivered to pregnant women in the chosen communities. 



\section{Conclusion}

An essential component of the SMART project was the testing of a model of maternal and neonatal care consisting of an intensive community-based intervention, supplemented by refresher training of static facility care providers. The community-based intervention focused first of all on education through support groups for women and for men, each of which met six times to learn about maternal and neonatal health care. For both the community mobilization activities and their IEEC supporting materials the depth of the interventions was a great strength. However, whether it is feasible for them to be introduced and sustained throughout Pakistan remains to be seen. There is an important need for new strategies that can provide education in depth with greater efficiency, and at the same time provide additional multi-directional support for the aims and activities of the SMART project.

\section{Community Mobilization}

The community mobilization strategy was an attempt to provide information in depth to childbearing women and their families, and to mobilize communities to support better response to maternal and neonatal activities. A large, integrated set of activities was undertaken that involved substantial proportions of both women and men in the communities. Most centrally, these activities involved holding intensive support groups for women and men and organizing health communities for better liaison with transport options and with the formal health system. These activities, in addition, were linked to training of the two types of health providers routinely based in villages, the LHW and the dai. These activities were well received in the communities by both women and men, and can be shown to have had substantial effects on community knowledge and practice (see SMART Report 3: Change in Knowledge and Behavior of Women and Families).

These accomplishments required a great deal of external human resource inputs, and took considerable time. An important factor reducing the time-efficiency of the project was the social fragmentation of the communities. An expectation that a facilitator, for example, could conduct several support groups and train additional facilitators to work in other parts of the community proved untenable because of this fragmentation.

The longer-term impact of this effort cannot be determined at this time, but it is likely that the effects would be substantially strengthened by sustained follow-up over time. This need 
not be as intense as the initial interventions, but would give needed support to the processes by which change occurs over time. The longer the period of SMART project involvement, the greater was the level of community acceptance and support; but the departure of the project came well before the needed changes in community understanding and practice were complete.

\section{IEEC}

To make support groups effective, printed and audio materials were needed both to guide the discussions and to serve as reference materials for the communities, and in particular the mothers. For this purpose, three sets of material were prepared for sharing with participants and the community generally: a detailed pictorial instruction booklet, a matching audiocassette, and an antenatal care card for pregnant women to keep with them.

These materials were quite specific to the needs of the project, though certainly aspects of them were quite general to Pakistan; for example, most rural Pakistani women are illiterate, so pictorial rather than written materials are widely appropriate. The health requirements of childbearing women are universal, so the basic points being conveyed through the SMART project were applicable to the whole of Pakistan. Moreover, the general culture of Pakistan, including beliefs and practices surrounding childbearing, has many commonalities throughout the country, so women throughout the country will be able to recognize themselves and their situations in these materials.

In two important ways, however, these materials were made to fit the particular needs of the SMART project. The most important of these is their use as core materials for the support groups. Since these involved six one-hour sessions, the intent was to cover considerable information in detail, rather than to get across a small set of simple messages. The materials, particularly the booklet and the cassette, contain more information than is often given in community education materials. Project staff attempted to make the content interesting and understandable, both through the pictorial formats and through the use of stories to illustrate particular issues.

The second area of specificity was in cultural detail. Pictures were made to be specific to DG Khan, for example, in dress styles or the layout of a room. A substantial effort went into making the details of the messages specific to the beliefs and practices highlighted during formative research. In this way, every attempt was made to make respondents feel that the IEEC materials reflected a strong level of knowledge of their own circumstances. 
IEEC materials were widely distributed. More than 29,000 booklets (i.e., more than 1 for every 2 married women of reproductive age in the CBI area) were handed out, along with more than 24,000 cassettes. The 4,390 ANC cards distributed represent about 1 for every 3 pregnant women in the CBI area over the course of a year. According to the household survey, 66 percent of respondents had received or seen the IEEC booklet.

Knowledge, and in some areas practice as well, in the CBI areas improved substantially during the project period. It is difficult to separate out the effects of the IEEC materials from other activities, particularly the support groups they were intended for. But it is clear that women who had seen or received IEEC materials within the CBI area had better profiles of knowledge and practice than those who did not. During follow-up research, respondents were uniformly complimentary about the materials, and there were rarely negative comments about such issues as length or lack of interest. The materials were effective; whether they were better than some other materials might have been could not be determined.

Under what circumstances might the IEEC materials developed for the SMART project be used in other programs? The following observations are relevant to that question:

- In programs where MNH education is undertaken at a level of intensity similar to the SMART project, these materials may be suitable for use throughout Pakistan.

- Conversely, they are probably not appropriate where there is little teaching support, or where the aim is to get across a few simple messages.

- It is not necessary to adapt such materials to the cultural details of a particular locality. While the fact that these materials represented the specifics of DG Khan was appreciated, we doubt that much would have been lost if the materials had reflected the specifics of another part of Pakistan. Small variations in circumstances are amenable to training solutions, without the trouble and expense of preparing new materials for a specific location.

- Whether these materials can be used without adaptation in other parts of South Asia, where circumstances are similar but language and culture differs, is doubtful. However, they may well serve as a useful model for adaptation.

- In circumstances in which the messages would differ significantly from those of the SMART project, a decision would be needed as to whether the differences are sufficient to warrant the development of new materials.

- Neither this nor any other such material represents an adequate solution in itself. A single, short-term education program is not sufficient to cause major changes in behavior or health in the absence of longer-term follow-up or substantial improvements in service delivery. 



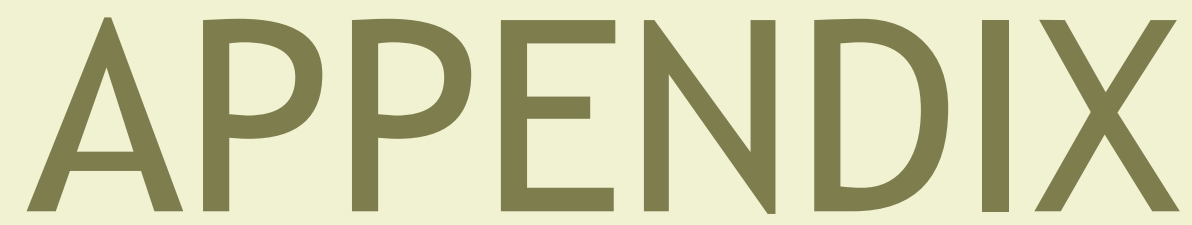





\section{Appendix 1. Description of client-centered approach training ${ }^{44}$}

\section{Objectives, concepts, techniques}

The following is a very brief description of the objectives and concepts of CCA training. The manual itself, The Client-Centered Approach to Reproductive Health: A Trainer's Manual, which takes the trainers through the training process step-by-step within each session, describes the techniques used in the training.

\section{Training objectives}

- Clarify and explain the link between self-awareness, health and development

- Identify participants' attitudes, prejudice and behaviors, so as to facilitate a positive change in them

- Communicate more effectively

- Increase their awareness regarding gender relations and it's link to health

- Give respect and develop rapport with clients

- Identify the reproductive health needs of clients beyond the immediate problem through a process of information exchange

- Assess the client's domestic/social background affecting those needs/situations

- Identify and respect clients' needs

- Apply negotiation skills to meet the identified needs of clients, and empower them through an equal information exchange

\footnotetext{
${ }^{44}$ The same manual was used for client-centered approach training for providers in the health systems interventions and the community-based interventions. Note: for those interested, a schedule for clientcentered approach training is available.
} 


\section{Training Concepts}

\section{Self-Awareness}

Through sharing experiences and through exercises, participants in CCA training develop better self-awareness, recognizing their own strengths and weaknesses, and learning how to use their strengths to serve their clients.

\section{Gender}

The session on gender is used to help participants understand the difference between sex and gender and become sensitized to the concept of gender. After this exercise, a service provider is more likely to provide his/her services without gender discrimination.

\section{Communication}

The session on communication focuses on interpersonal communication. Participants learn about the communication process, elements of communication, barriers affecting the communication process, and verbal and non-verbal communication. They also learn that feedback is a very important component of communication, especially in client-provider interaction, where it is essential to ensure the client has understood instructions.

\section{Behavior}

The session on behavior provides insight into the different types of behavior exhibited by people. In order to change behavior, one needs to begin by changing beliefs and values. Participants are better able to understand how their behavior affects the behavior of others.

\section{Power}

In the session about power, types of power are defined, and "power to," "power with" and "power within" are explained. How to empower those who are powerless is also discussed. The responsibilities of those with power are brought out, as well as the idea that sharing power does not diminish one's own power, but instead enhances prestige and honor.

\section{Methodology}

The following techniques are used to help participants interact with each other during the training (as well as to hold their interest): go around, brainstorming, group discussion, case study, role-play, games and energizers, and videos. 


\section{Appendix 2. Training of trainers in the client - centered approach}

The first step in CCA training was training the trainers. Those training included the two teams of CCA trainers, the technical trainers in obstetrical care for doctors and paramedics, and the trainers who would run the LHW and dai trainings. This was done so that CCA concepts would at the forefront of all project interventions.

A three-member team of Population Council master trainers trained all of the 14 trainers. The ten-day training of trainers was carried out from 9-19 June 2004 at the District Health Development Center (DHDC), with a couple of sessions at the Population Council's DG Khan staff house. The course material had been prepared by the Population Council and used in previous trainings.

In the case of the district health system providers, the Population Council staff believed that it was important to provide training that could become part of the district health system. Therefore, the Council decided that the training of all of the health care providers would be done not by Population Council staff but by individuals who operated within the district health system. In this way, once these individuals were taught to understand and use the training, they would enhance the capacity of the district health system for greater sustainability of proper maternal and neonatal health care procedures.

The selection process for the trainers who would be taught to train the district public health providers was done through talking to staff, advertising, and asking the Executive District Officer (EDO) (Health) to refer people. Criteria for the selection of district trainers were: (1) academic requirements;45 (2) relevant training/work experience; (3) experience as a trainer; (4) knowledge of the district health system; (5) personal qualities (vocal, clear, confident and social); and (6) knowledge of the local language. Through this process, two teams were created: each team consisted of a male doctor, a female doctor and a social scientist.

Training was broadly divided into two phases of five days each. The first five days provided an orientation to topics fundamental to the client-centered approach, giving the participants

\footnotetext{
${ }^{45}$ Appropriate training and/or degrees according to their job title.
} 
first-hand experience of the process of self-awareness. This included behavior change, gender sensitization and power dynamics, and, throughout, the primary emphasis was on improving trainees' communication skills.

The second phase dealt with training methodologies and tools to build the training capacity of the participants. Participants delivered training sessions and were given feedback from fellow participants and from master trainers. Details of each CCA session were reviewed so the district trainers would understand the training process when they were conducting the training (e.g., time allocation, required supplies, objectives, proceedings, synthesis and training material).

The proceedings of the training of trainers (TOT) were video recorded for district trainers to use as a training guide for future reference. 


\section{Appendix 3. Description of dai training: client- centered approach and technical}

\section{General features of dai training}

- Eight days of training

- Client-centered approach (CCA) sessions followed by technical sessions

- Experiential learning drawing on experiences of participants

- Atmosphere of equality and respect

- Participatory-adult learning methods (for illiterate participants)

- Traditional beliefs questioned with appropriate messages

- Hands-on skill development (simulations)

- Safe delivery kit introduced

- Liaison with LHWs and health facility staff

\section{Client-centered approach}

The client-centered approach is described in a box at the beginning of section 1; the concepts/content of CCA training are presented in appendix 1. CCA training for dais is nearly the same as that for other providers, though trainers emphasize the concept of the ideal dai. Through brainstorming, dais reach consensus that their role is pivotal in the management of maternal and neonatal health issues and that this important role demands that an ideal dai should have correct knowledge and skills, and also carry out practical steps while establishing good interaction with the client. One way in which dai CCA trining focuses on their particular role in service provision is with the training on power during which dais discuss their role in dealing with power dynamics within households, and how a dai can empower mothers in the home, or any other place, with the help of information and negotiation. They learn specifically how mothers can be empowered regarding healthrelated issues 


\section{Technical topics}

\section{Reproductive system}

Dais are given a brief overview of the reproductive system and basic anatomy so they learn about the functions of the body related to gestation and birth.

\section{Antenatal care}

Dais learn the importance of antenatal care. During discussions on various issues related to pregnancy, dais are informed about positive antenatal care practices as well as harmful practices.

\section{Delivery}

Dais are given a comprehensive lesson on the simple aseptic measures they can take, and how can these prevent fatal results. They are informed about the dangers of giving uterotonic injections in the absence of good monitoring, which is available in hospitals only. The potential for infections is discussed in regard to frequent vaginal examination.

- Clean delivery kit: Dais are taught the use of the clean delivery kit.

- Money and transport: The issues related to money and transport, which are very critical during an obstetrical emergency, are an integral part of this session. Various options are discussed.

\section{Postnatal care}

Contact of clients and care providers during this phase is low when there is no apparent problem. Some conditions that occur during this period, like infections, bleeding, etc., may become life threatening. Therefore, the importance of this phase in specific situations is discussed during training. Dais are provided with an opportunity to talk about advice related to diet, rest, feeding and family planning.

\section{Neonatal care}

This topic has been added to as a separate section of the curriculum for dai training, which has not been done before. Focus is on the immediate care of the newborn, which includes cleaning, warmth, bathing, use of colostrums and breastfeeding. Dais learn management of these through hands-on training sessions using models. 


\section{Appendix 4. Manuals used in technical (basic EmOC) training of doctors and paramedics}

Topics covered in manual on Healthy Mother, Healthy Infant:

- Antenatal care

- Natal care

- Postnatal care, including danger signs

- Antepartum hemorrhage

- Pre-eclamptic toxemia

- Obstructed labor

- Postpartum hemorrhage
- Perineal tear

- Puerperal sepsis

- Surgical scrubbing technique

- Artificial resuscitation

- Perpeurium

- Family planning

Topics covered in manual on Care of Newborn:

- Care of neonate after delivery

- Neonatal emergency resuscitative measures APGAR and artificial resuscitation

- Vaccination

- Neonatal nutrition

- Breastfeeding

- Problems of lactating mothers
- Problem of breastfeeding baby

- Refusal of breastfeeding

- Failure to establish breastfeeding

- Low birth weight babies' problems and their solution

- TORCHES

- Multifactor neonatal problems

Topics covered in manual on Practical Skills for Care of Mother and Infant:

- Procedures for maternal and neonatal care (e.g., infection prevention, taking blood pressure, checking urine, etc.)

- Orientation to family planning 


\section{Appendix 5. Description of steps for support groups}

Table A.5. Steps and descriptions utilized in sup port groups

\begin{tabular}{ll}
\hline Step & Description \\
\hline $\begin{array}{l}\text { Introduction of } \\
\text { the topic }\end{array}$ & $\begin{array}{l}\text { After settling down, the facilitator introduced the maternal and neonatal health } \\
\text { care topic of the day. He or she would give a brief overview and then invite } \\
\text { participants to share their views. }\end{array}$ \\
Brainstorming & $\begin{array}{l}\text { Participants shared their experiences and observations on the issues related to the } \\
\text { day's topic. The facilitator would try to get views from all participants. }\end{array}$ \\
Story (from & $\begin{array}{l}\text { After a brief discussion, the facilitator ran an audiocassette. Participants would } \\
\text { audiocassette) }\end{array}$ \\
$\begin{array}{l}\text { listen to the story and match the story with the pictures in their booklet on that } \\
\text { topic. The facilitator might add something at the end of the story. }\end{array}$ \\
$\begin{array}{l}\text { After the story, the facilitator started the discussion on the topic again. This } \\
\text { discussion would be based on their previous knowledge, experiences and } \\
\text { observations plus the new information from the cassette. As most participants had } \\
\text { been performing dangerous practices or had incorrect information, a discussion } \\
\text { would occur about correct practices. Even so, some group members would still } \\
\text { hold to their previous belief. The facilitator would try to bring the discussion } \\
\text { toward recognizing correct healthy practices. }\end{array}$ \\
$\begin{array}{l}\text { After the discussion, important messages would run on the cassette player; these } \\
\text { were also in the booklet. }\end{array}$ \\
$\begin{array}{l}\text { Messages } \\
\text { Afrap up by the messages, the facilitator ended the day's session by summarizing the } \\
\text { session/information, emphasizing healthy practices and messages. }\end{array}$ \\
\hline
\end{tabular}




\section{Appendix 6. Composition of focus groups for preparatory fieldwork}

Table A.6.1. Number of focus groups for preparatory fieldwork, by topic and type of group

\begin{tabular}{lllr}
\hline Tehsil & FGD topics & Female/Male & Number \\
\hline \multirow{2}{*}{ DG Khan } & Neonatal care & Female & 10 \\
& Iron tablets, use & Female & 10 \\
& Antenatal care & Female & 10 \\
& Male involvement & Male & 10 \\
& LHWS & Female (LHWs) & 2 \\
Taunsa & Neonatal care & Female & 4 \\
& Iron tablets, use & Female & 4 \\
& Antenatal care & Female & 4 \\
TOTAL & Male involvement & Male & 2 \\
\hline
\end{tabular}


Table A.6.2. Number of focus groups for preparatory fieldwork, by cluster and type of group ${ }^{a}$

\begin{tabular}{|c|c|c|c|c|c|}
\hline Tehsil & Cluster name & Male FGDs ${ }^{\mathrm{b}}$ & Female FGDs ${ }^{c}$ & LHW FGDs & Total \\
\hline \multirow[t]{11}{*}{ DG Khan } & Bait Mohri & 1 & 3 & 0 & 4 \\
\hline & Darrh Opela & 1 & 3 & 0 & 4 \\
\hline & Ghuman & 1 & 3 & 0 & 4 \\
\hline & Shah Sadar Din & 1 & 3 & 1 & 5 \\
\hline & Ponner & 1 & 3 & 0 & 4 \\
\hline & Noor Wahi Sydhran & 1 & 3 & 0 & 5 \\
\hline & Doodah & 1 & 3 & 0 & 5 \\
\hline & Dhool & 1 & 3 & 0 & 5 \\
\hline & Bakhar Wah Sharqi & 1 & 3 & 0 & 5 \\
\hline & Jiani & 1 & 3 & 0 & 5 \\
\hline & Mana Ahmadani Sharqi & 0 & 0 & 1 & 1 \\
\hline Total & & 10 & 30 & 2 & 42 \\
\hline \multirow[t]{4}{*}{ Taunsa } & Veho Wa Shumali & 0 & 3 & 1 & 4 \\
\hline & Litri Shumali & 0 & 3 & 0 & 3 \\
\hline & Jhoke Rohail & 1 & 3 & 0 & 3 \\
\hline & Aqu Pur & 1 & 3 & 0 & 4 \\
\hline Total & & 2 & 12 & 1 & 15 \\
\hline TOTAL & & 12 & 42 & 3 & 57 \\
\hline
\end{tabular}




\section{Appendix 7. Detailed description of IEEC booklet ${ }^{46}$}

A short description of the contents of the IEEC booklet is contained in the body of the report. For anyone interested in producing IEEC material, this more complete description may be helpful.

\section{Front page}

The cover page of the booklet depicts the various stages of life a woman goes through. A young woman is seen on the far left side of the page standing on the first step. The scenery behind the young girl depicts a rural village, with an animal drawn plough and very little development. This symbolizes the lack of empowerment and knowledge as far as the young girl is concerned. She lives in a poor village and has very little or no access to education with which to empower herself.

The scene depicted in the second stage is that of a married woman, who is walking alongside her husband and is further along the steps of life. In the background some obvious changes have taken place. Instead of animal drawn ploughs, the use of machinery can be noted. This suggests a change of times, an increase in technology and greater prosperity. It also symbolizes the beginning of empowerment for the woman, who now has access to information and education.

Finally, the third part of the picture depicts the woman in later years of her life along with a female child. The woman is now empowered and does not need to walk alongside her husband. She is independent and is able to make decisions for herself with the help of the knowledge and information available to her. The young child is dressed in yellow (the same color as the sun), which symbolizes knowledge and empowerment. The young child will therefore be very different from her mother, who was not empowered as a young girl. As well, the scenery in the background depicts prosperity, technology and development, symbolic of the growth that has taken place in the woman over the stages of her life.

\footnotetext{
${ }^{46}$ Note: For copies of the complete IEEC booklet and audiocassette (in Seraiki, Balochi, or Urdu), contact the Population Council. Limited copies are available without charge.
} 
Title

For the development of this booklet, qualitative work was done, various issue were pointed out, and a title was decided upon. There were many options for the title of the booklet including Light (Ujala), Lessons of life (Sabak zindage kay), The role of women in childcare (Bachay ki nigehdasht main maan ka kirdar). Finally, at the suggestion of the PC Islamabad staff and IEC experts, the title chosen was the same title that was chosen for the BSMI project booklet. The title was, "Mothers and Motherhood Everlasting" (Maan or Mamta Rahay Salamat). Different aspects were considered in the selection of the title, including the ease with which it could be understood and its relevance to the SMART project. The opinion of IEC experts was sought prior to finalizing the title. The title was chosen due to the strong emotions it would potentially incite in mothers.

\section{Chapter outlines}

There are seven chapters in the IEEC booklet, each containing a different message related to maternal and newborn health. Each chapter was assigned a different color (with a colored bar or stripe of that color across the top of the pages): brown for nutrition, dark blue for antenatal care, red for danger signs, pink for safe delivery practices, purple for postpartum care, blue for neonatal care and green for family planning methods. The seven chapters are as follows:

\section{1) Brown stripe - Masi Sughra's advice for girls and women on nutrition}

This chapter contains approximately fifteen messages, three of which are related to childhood nutrition, while the rest stress the importance of nutrition during pregnancy. A character by the name of Masi Sughra emphasizes the importance of ensuring that both male and female children receive adequate nutrition, without any preference for the male over the female child. It was stressed that a healthy girl would grow up to be a healthy mother who will then bear healthy children. As well, proper nutrition during pregnancy was emphasized in this chapter. In DG Khan, it is widely believed that a pregnant woman should not eat too much for fear that her baby will become too big and therefore cause problems during delivery. Such wrong ideas and practices were addressed in this chapter, while the value of nutrition was emphasized.

\section{2) Violet stripe - Baji Kulsoom's advice on care of women during pregnancy}

This chapter contains ten messages regarding antenatal care, and is presented from the view of a character with the name of Baji Kulsoom. In DG Khan, most people prefer the assistance of untrained dais. Therefore, this chapter outlines the importance of seeking antenatal care from a trained LHW, who is able to give pregnant women TT injections and iron supplements. The booklet also instructs women to avoid tobacco and other harmful 
substances during pregnancy, due to their negative affects on the fetus. This chapter also offers alternatives for certain types of foods that are necessary during pregnancy. For example, women are encouraged to eat lentils during pregnancy if they are unable to afford meat, or drink lassi instead of milk. Women are also encouraged to double their diet during pregnancy.

\section{3) Red stripe - Complications and dangers signs during pregnancy}

For each danger sign, the importance of saving money, arranging transport, blood and money, and seeking medical help in a timely manner was emphasized. As well, the messages stressed that the family of the woman suffering from a complication must take responsibility for her at such a time. Each story ended at a hospital to ensure that the audience realized the end of each story and the beginning of another.

The danger signs for five of the most common obstetric complications:

\section{- Red stripe - Fits during pregnancy (eclampsia) (Rashida's story)} Toxemia during pregnancy: The booklet indicated the importance of seeking help from a trained health professional as soon as signs of toxemia appear. The story of a woman named Rashida was presented in the booklet, and her experience suffering from toxemia during pregnancy was shared. The use of a spoon with a cloth wrapped around it, used to ensure that a pregnant woman suffering from toxemia does not stop breathing, was presented in the booklet.

\section{- $\quad$ Red stripe - Bleeding during pregnancy (Wasoomai's story)}

The second story given was that of a woman named Wasoomai; the story outlines the importance of seeking immediate help in the event that a woman starts bleeding during pregnancy. It also outlines the dangers of not seeking treatment in a timely manner. The use of an untrained dai was discouraged strongly.

- Red stripe - Prolonged labor (Bachal Mai's story)

The story in this section was about a woman named Bachal Mai. It emphasized the importance of noting timings as soon as labor pains begin. It also highlights the wrongful practices that people in the district of DG Khan often follow, such as giving the pregnant woman injections during labor, or asking the pregnant woman to push the baby out prematurely, causing tears in the uterus. The messages in the booklet encouraged the involvement of husbands during labor through improved communication.

- Red stripe - Postpartum hemorrhage (Kaneez's story)

The fourth story was about a woman named Kaneez; the story emphasized the fact that postpartum bleeding should be taken very seriously as it is indicative of complications. The message encouraged people to determine the reason for 
hemorrhaging, and to ensure that the placenta has been completely removed from the uterus following delivery. As well, the message stressed the importance of seeking medical attention as soon as bleeding starts.

- Red stripe - Puerperal sepsis (temperature after delivery and entry of germs) (Zohra's story)

Sepsis is caused by unsafe delivery practices. The booklet stressed the importance of having trained health professionals or trained dais assist with deliveries, and provided the story of a woman named Zohra who suffered from perpetual sepsis. The message also stated that fever in a woman who is in her postpartum period should not be ignored. The use of safe delivery kits and the necessity of a safe delivery environment were greatly emphasized in this chapter.

\section{4) Pink stripe - Safe delivery practices and birth preparedness}

This chapter of the booklet contained twelve messages and outlined safe delivery practices. The story of a woman named Nasreen stressed the necessity of trained dais, safe delivery kits, a well-rounded diet before, during and after pregnancy, adequate antenatal and postpartum care and a clean delivery environment. Women were encouraged to make their dais wash their hands and cut their nails prior to delivery, and were told not to let the dai conduct too many physical examinations during the labor period due to the risk of disease. The pregnant woman was encouraged to breastfeed her child soon after delivery, as well as to stay nourished herself.

\section{5) Purple stripe - Care of mother and child after delivery (postpartum care)}

This chapter contained six messages related to postpartum care, and a woman named Ameer Mai tells the story. The messages emphasized that a woman should stay clean and warm after delivery, and ensure that her diet was well rounded. She should also have obtained postnatal care to ensure that she was at no risk of developing complications.

\section{6) Light blue stripe - Care of newborn; health of mother and child (neonatal care)}

This chapter contained eighteen messages regarding neonatal care. The messages discouraged people against the common wrongful practices that take place in DG Khan. Breastfeeding was encouraged, and women were told to feed their newborn babies colostrums. The correct way to cut the umbilical cord was also taught, and an awareness of the complications that may occur in a newborn was emphasized. The message stressed the importance of keeping a baby warm following birth, and encouraged mothers to have their children weighed. There was a common belief among the people of DG Khan that a child will perish either on the eighth day, the eighth week, the eighth month or the eighth year following birth. The message encouraged women to take their newborns for regular 
checkups after delivery.

\section{7) Green stripe - Advice of Masi Sakina and family planning}

The last chapter discussed family planning, and consisted of four messages. A woman by the name of Masi Sakina emphasized the benefits of having fewer, healthier children, and highlighted the disadvantages of having large families. The various methods of contraception were outlined and a description of how to use each method was included.

Poem

A poem (nazam) regarding women was also included in the booklet. The purpose of this poem was to highlight the different roles of women (as mother, daughter, wife and sister) and to encourage people to treat women with respect.

\section{Last page}

The last page of the booklet is an aid that allows uneducated persons of DG Khan to learn how to count. This is aimed at helping people keep count of the hours in which a pregnant woman is in labor or the length of time during which a pregnant woman suffers from a complication.

\section{Back page}

A picture of the seating arrangement of FGDs is included on the back of the booklet showing participants sitting in a circle, each with his/her own copy of the IEEC booklet. Finally, an audiocassette player can be seen in the center of the circle. A facilitator, who leads the FGD, can also be seen in this picture. 


\section{Appendix 8. Detailed description of ANC card}

A short version of this description of the pages of the antenatal (ANC) card is contained in the body of the report. For anyone interesting in producing IEEC material, this more complete description is provided.

\section{Front page of ANC card}

The cover shows a woman holding a newborn baby, with A Card for Care of Pregnancy and Neonate: Care of Women during Pregnancy and Delivery written at the top and Health Mother Gives Birth to Health Child written at the bottom (English translations).

\section{Section 1: Routine antenatal check-up}

First picture: pregnant woman having blood pressure checked.

Second picture: woman's eyes being examined for anemia

Third picture: woman's abdomen being checked for status of pregnancy

Fourth picture: woman receiving tetanus toxoid shot

\section{Section 2: Danger signs during pregnancy}

First picture: woman taking folic acid (to avoid anemia, a danger sign)

Second picture: woman experiencing severe headache

Third picture: woman being checked for edema

Fourth picture: woman on bed experiencing antepartum bleeding

\section{Section 3: Safe delivery practices and birth preparedness}

First picture: Woman preparing home and gathering materials for delivery

Second picture: dai preparing for delivery by cutting nails

Third picture: dai washing hands before delivery

Fourth picture: cutting and tying the cord 
Section 4: Danger signs of delivery and postpartum

First picture: woman in prolonged labor

Second picture: delayed expulsion of placenta

Third picture: excessive bleeding postpartum

Fourth picture: Methods of family planning (to be discussed postpartum)

Section 5: Immediate newborn care

First picture: mother wrapping newborn

Second picture: dai cleaning newborn's mouth

Third picture: dai washing newborn's eyes and face

Fourth picture: dai bathing the baby

Section 6: Postpartum care

First picture: mother bathing postpartum

Second picture: mother eating properly

Third picture: mother with fever

Fourth picture: Mother with swelling in breast

Section 7: Early infant care

First picture: baby properly wrapped and placed

Second picture: baby being breastfed

Third picture: baby being weighed in health center

Fourth picture: baby receiving immunization 


\section{Appendix 9. Names of individuals involved in SMART interventions}

1. Community Based Interventions (CBI)

\begin{tabular}{ll:ll}
\hline Name & Designation & Name & Designation \\
\hline Dr. Abdul W ajid & Lead Person & &
\end{tabular}

\section{Development of IEEC}

Ashfa Hashmi

Asim Abbas

Aqeela Bano

Sadaf Yasmeen

Nazish Batool

Humaira Bibi

Irum Khaliq

\section{Community mobilization}

Ashfa Hashmi

Aqeela Bano

Samina Mustafa

Sumaira Mushtaq

Mohsana Khekanshan

Sadaf Yasmin

Rabia Ishaque

Nazish Batool

Shagufta Nawaz

Rubeena Bibi

Sadia Sharif

Humaira Bibi
Lead Person

Logistic Coordinator

Supervisor

Supervisor

Supervisor

Interviewer

Interviewer

Lead Person

Field Coordinator

Supervisor

Supervisor

Supervisor

Supervisor

Supervisor

Supervisor

Supervisor

Assistant Supervisor

Assistant Supervisor

Assistant Supervisor

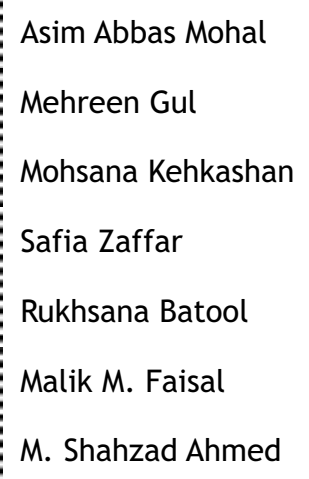

Asim Abbas Mohal

Mehreen Gul

Mohsana Kehkashan

Safia Zaffar

Rukhsana Batool

Malik M. Faisal

M. Shahzad Ahmed

Field Coordinator

Interviewer

Interviewer

Interviewer

Interviewer

Interviewer

Typist + Interviewer
Assistant Supervisor

Assistant Supervisor

Assistant Supervisor

Assistant Supervisor

Assistant Supervisor

Assistant Supervisor

Field Coordinator

Assistant Supervisor

Assistant Supervisor

Assistant Supervisor

Assistant Supervisor

Assistant Supervisor 


\begin{tabular}{ll|ll}
\hline Name & Designation & Name & Designation \\
\hline \multicolumn{2}{l}{ Training of community-based service providers } & & \\
Zeba Tasneem & Lead Person & Safia Zafar & Supervisor \\
Lubna Shireen & Lead Person & Shagufta Noureen & Supervisor \\
Shahzadi Nausheen Gul & Supervisor & Farzana Tehseen & Interviewer - FGDs \\
Effat Rubab & Supervisor & Aamir Rashid & Assistant \\
Farzana Parveen & Supervisor & Muhammad Saeed & Assistant \\
Noor Jahan Ara & Supervisor & Rafiq Ahmad & Assistant \\
Ruksana Irshad & Supervisor & Muhammad Arif & Typist \\
\hline
\end{tabular}

\section{Health Services Interventions (HSI)}

\begin{tabular}{ll|ll}
\hline Name & Designation & Name & Designation \\
\hline Dr. Zakir Hussain & Lead Person & Dr. Uzma Rehman & Trainer - Tech. \\
Saima Pervaiz & PC- ISB & Dr. Anila Saqib & Facilitator - Tech. \\
Dr. Sajid Waheed & Training Coordinator & Dr. Saima Sultan & Facilitator - Tech. \\
Dr. Mazhar Ali Jaskani & Trainer - CCA & Amjad Waheed & Asst.Facilitator - Tech. \\
Dr. Munaza Batool & Trainer - CCA & Sadia Sharif & Trainer Assistant - CCA \\
Dr. Zia ul Hassan & Trainer - CCA & Hina Sumreen & Trainer Assistant - CCA \\
Dr. Sobia Ali & Trainer - Tech. & & \\
\hline
\end{tabular}


